CIUDAD Y TERRITORIO

ESTUDIOS TERRITORIALES

ISSN(P): 2697-231X; ISSN(E): 2697-2328

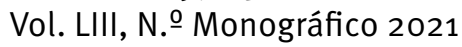

Págs. 61-82

https://doi.org/10.37230/CyTET.2021.M21.04

CC BY-NC-ND

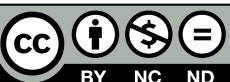

\title{
Las consecuencias de la turistificación en el centro de las grandes ciudades. El caso de Madrid y Barcelona
}

\author{
Montserrat CRESPI-VALLBONA ${ }^{(1)}$ \\ Marta Domínguez-PÉrez ${ }^{(2)}$
}

(1)Doctora. Profesora agregada. Facultad de Economía y Empresa. Universitat de Barcelona ${ }^{(2)}$ Doctora. Profesora titular. Facultad de Ciencias Políticas y Sociología. Universidad Complutense de Madrid.

Miembro de TRANSOC

RESUMEN: En el marco de las grandes ciudades españolas y durante las últimas décadas, Madrid y Barcelona presentan unas lógicas similares en cuanto al alza de precios de la vivienda y al desfase de la capacidad adquisitiva de su población. Uno de los factores que ha incidido en que estas dos ciudades despunten por encima del resto manifestando una extrema dificultad en la compra y/o alquiler de la vivienda es el fenómeno del turismo y la intensiva turistificación (Harvey, 2004), además de otros procesos correlacionados. El centro de la ciudad es el más afectado por éstos, siendo uno de los efectos más graves el del desplazamiento de los sectores más vulnerables en beneficio de los más acomodados. A través de dos casos de estudio de barrios vulnerables en el centro de la ciudad en Madrid y Barcelona, se pone en evidencia cómo operan los procesos de desplazamiento de la población en dos niveles: cuantitativo y cualitativo. Se observa que el discurso que se gesta entorno a estos barrios, promueve el desplazamiento poblacional acompañando al resto de estrategias más económicas.

PALABRAS CLAVE: Turistificación; Vulnerabilidad; Pobreza; Madrid: Barcelona; Vivienda; Centro urbano.

\section{The consequences of touristification in the center of large cities. The case of Madrid and Barcelona}

ABSTRACT: In the context of Spanish big cities and during the last decades, Madrid and Barcelona reveal similar logics related to the rise of housing prices and the population's mismatch of purchasing power. Tourism and intensive touristification are determinant factors that explain why these cities

Recibido: 03.07.2020; Revisado: 23.10.2020.

Correo electrónico: mcrespi@ub.edu; N. ${ }^{\circ}$ ORCID: https://orcid.org/0000-0001-8267-4786

Correo electrónico: madoming@ucm.es; N. ${ }^{\circ}$ ORCID: http://orcid.org/0000-0002-3145-6671

Las autoras agradecen los comentarios y sugerencias realizados por los evaluadores anónimos, que han contribuido a mejorar y enriquecer el manuscrito original. 
excel from the rest, showing extreme difficulties face to housing purchasing and/or renting (Harvey, 2004). Urban centre is the most affected space due to these processes, being one of the most serious effects the displacement of the most vulnerable citizens in favour of the most well-off ones. Two case studies of two most vulnerable neighbourhoods in the centre of Barcelona and Madrid show how these displacements of population operate in two levels -quantitated and qualitative- and how the population's displacement goes in parallel to the rest of more economic strategies.

KEY WORDS: Touristification; Vulnerability; Poverty; Madrid; Barcelona; Housing; Urban centre.

\section{Introducción}

J iversas son las dinámicas urbanas que resultan de interés en Barcelona y Madrid tanto por ser las dos ciudades más grandes del panorama español como por ser la punta del iceberg de muchas de las tendencias que se evidencian. La riqueza y la vulnerabilidad, la segregación y la desigualdad son procesos más intensos y extremos en el caso de ambas. También el atractivo de estas ciudades para el turismo es intenso y también su impacto, principalmente en el centro urbano, donde se concentra el patrimonio y los recursos de ocio y cultura, así como donde se evidencian las mayores oportunidades para el capital.

Pero uno de los impactos más lesivos es sobre los residentes tradicionales del centro, sus habitantes. Si bien en el centro, una gran proporción de estos pertenece a las clases acomodadas; también, especialmente en algunas áreas (como las que aquí se analizan), pertenecen a las clases populares, inmigrantes, etc. Esto sucede desde que, a partir de la década de los ochenta, una gran parte de aquellos residentes (aunque no todos a diferencia de las ciudades anglosajonas) salieron hacia las periferias mediante desplazamientos, por un lado, obligados y por el otro, voluntariamente, dejando a los sectores más vulnerables en dichos espacios centrales. Son estos los que en la actualidad se ven más afectados por estas dinámicas, como resalta Sassen en Expulsiones (2015). Procesos de expulsión que se relacionan con la privación del derecho a la ciudad como consecuencia de las transformaciones urbanas que son de manifiesta magnitud global según Smith (SMITH, 2002) o Lees (LEES, 2016). De este modo, mediante "formaciones predatorias" que son instrumentos de políticas públicas, de avances tecnológicos, financieros y de mercado, al servicio de grandes fortunas y de grandes corporaciones y gobiernos, se evidencia que:

\footnotetext{
"debajo de las especificidades nacionales de las diversas crisis globales, se encuentran tendencias sistémicas emergentes conformadas por unas pocas dinámicas básicas" (Sassen, 2015:15).
}

Así las ejecuciones ante los impagos de vivienda o el desplazamiento debido a la compra de edificios por parte de grandes corporaciones o del capital serían parte de esos instrumentos predatorios. El debate europeo vincula además estos procesos con los de suburbanización de la pobreza, como señalan HocHTENBACH \& MUSTERD (2018); aunque para el caso de Barcelona, por ejemplo, Porcel y otros (PORCEL \& al., 2018) no concluyen que la suburbanización de la pobreza sea lo que está sucediendo, sino que los datos no permiten evidenciarlo claramente, siendo necesarios estudios más profundos al respecto. Aquí se intentará definir el contexto discursivo que promueven estas tendencias.

Así pues, la lógica neoliberal en la ciudad afecta especialmente a sus centros, mediante tendencias aparentemente dispares e independientes (de gentrificación, trendificación, turistificación, estudentificación y financialización), pero conectadas en cuanto a sus efectos. Ello conlleva el desalojo de los actuales sectores populares, inmigrantes, mayores, etc. para ser sustituidos por sectores de nivel medio alto y por el capital financiero (ColomB, 2007; Cucó, 2013; NovY, 2017; SASSEN, 2015) en aras de una ciudad todavía más acorde con el nuevo orden internacional. Consecuentemente, ello tiene un impacto sobre la cohesión social y urbana muy devastador (SLATER, 2006). Es lo mismo que resalta también MosKowITZ (2017) en cuanto al proceso de gentrificación en varias ciudades americanas y lo que aquí resaltamos que subyace de fondo: que todos estos procesos son manifestaciones de una lógica más profunda, no sus causas, como dice este autor. Esto es, que son la manifestación de la lógica del capital: "gentrification is a system that places the needs of capital (...) above the needs of people" (MoskowITZ, 2017: 21).

Esta es también la particularidad del centro urbano donde las tendencias son más intensas $y$, sobre todo, por su impacto en los colectivos vulnerables a diferencia de otros espacios de la ciudad. Así, a pesar de que Madrid y Barcelona mejoran su nivel de renta media en el periodo analizado (desde 2001 a la actualidad), es, en 
los barrios del centro de menor nivel socioeconómico, concretamente en el Raval en Barcelona y en Embajadores (Lavapiés) en Madrid, donde se observan estas desigualdades y contrastes de forma más intensa (INFORME AXESOR, 2019). Ambos son los dos espacios de menor nivel socioeconómico de sus respectivos centros (INE, 2016) y que, tras la etapa de la recuperación económica después de la crisis de 2009 , se van a ver codiciados por el capital, las clases medias y altas originándose el desplazamiento de sus antiguos pobladores más vulnerables. Todavía es pronto para dilucidar qué pasará tras la crisis posterior de la pandemia 2020 por lo que el foco de análisis antes de la misma se detiene en esta.

La ciudad es el espacio donde desarrollar la ciudadanía y el pleno derecho como tal para todos sus residentes. Así lo puso de manifiesto Lefebvre con su derecho a la ciudad, o bien Jane Jacobs, y Harvey con la apropiación de la ciudad por parte de sus ciudadanos. Ahora bien, el problema surge cuando se dan dinámicas, tanto físicas como simbólicas, que expulsan o excluyen a unos en favor de otros (SASSEN, 2015). Es esto lo que suele ocurrir en el centro de las ciudades cuando el capital y sectores afines se apropian de dichos espacios expulsando y excluyendo a los sectores vulnerables.

$Y$ es que la centralidad todavía importa como así lo demuestra la Escuela de Sociología urbana latinoamericana frente a la Escuela de Los Angeles que presenta la ciudad como espacios donde no importa el valor del centro (LEZAMA, 2014). Las ciudades europeas y latinoamericanas, sobre todo, ponen de manifiesto que el centro cuenta por su valor estratégico, tanto física como simbólicamente, y por ello es tan relevante en el área urbana. Unos y otros sectores organizan el espacio físico y también el espacio simbólico para apropiarse del centro, acompañando las dinámicas de expulsión que se van retroalimentando entre sí. De este modo, tanto el precio de la vivienda como el cambio de estilo de vida central de los barrios pueden servir como disuasorios para la habitabilidad en dichos espacios para algunos colectivos.

Según Lefebvre, el derecho a la ciudad consiste, entre otros, en que la ciudad sea un espacio disfrutado por todos, que permita la autonomía para todos sus residentes, de manera equitativa; el espacio donde se evidencian las diferencias y contradicciones y donde ciertos grupos, o bien ciertos estilos de vida, puedan coexistir e incluso convivir, de manera que no sean segregados ni apartados o enviados a las periferias, ya no de la ciudad, sino de la vida urbana (URZÚA BASTIDA, 2012). No obstante, se constata la constitución de una elitización de los centros, de la presencia de una nueva comunidad cohesionada entorno a la oferta cultural y gastronómica, al consumo lúdico diverso (BAPTISTA, 2005), al margen de la exclusión y la desigualdad que se configura, mediante formas de vida radicalmente diferentes, en el nuevo escaparate de la ciudad.

\section{Objetivos y metodología}

Este trabajo pretende evidenciar cómo los centros de Madrid y Barcelona presentan dinámicas más extremas y diferenciadas del resto de grandes ciudades españolas (Valencia, Bilbao, Zaragoza o Sevilla), colocándose en cierto modo en la vanguardia de las mismas. Al mismo tiempo se hacen eco de las tendencias recientes urbanas de la turistificación que junto a otras dinámicas paralelas (financiarización, gentrificación, trendificación, estudentificación, desplazamiento simbólico, etc.) como expresiones de la lógica neoliberal; $y$ a través de procesos como el alza de precios, cambios en el comercio, dificultad de acceso a la vivienda, desahucios, cambio del entorno barrial simbólico, entre otros, operan tras la crisis conllevando como uno de sus más graves efectos: la expulsión de las clases tradicionales del centro de la ciudad hacia las periferias. Se configura así un centro para unos nuevos residentes y propietarios (HOCHSTENBACK \& MUSTERD 2018) dentro del proceso denominado de expulsiones que describe SASSEN (2015) como una lógica subyacente a diferentes procesos.

Para ello, nos centramos en los dos barrios de menor nivel de renta que todavía persisten en el centro urbano de ambas ciudades, El Raval y Embajadores, y donde se evidencia el proceso de expulsión de los remanentes sectores vulnerables en aras de la turistificación y otras dinámicas urbanas que promueven la apropiación de los espacios centrales para unos sectores en perjuicio de los más vulnerables como manifestación de dinámicas más profundas. En un marco español de predominio del régimen de propiedad frente al de alquiler, que ancla la población al espacio, es llamativo que, en espacios de concentración de régimen de alquiler como el centro urbano, los procesos de movilidad residencial pueden ser algo más intensos.

En esta investigación se evidencian estos procesos a través sobre todo del nivel discursivo de sus residentes que corporeizan dichos discursos naturalizándolos y haciendo de ellos una realidad que acompaña al desplazamiento. 
Esta investigación tiene lugar en el marco del proyecto I+D, Influencia de los cambios en los regímenes de producción y acceso a la vivienda sobre la restructuración social de las grandes ciudades españolas CSO2017- 83968-R (20182020) que ha analizado el marco comparativo de tendencias en las seis grandes ciudades españolas entre 2001 y 2011 (considerando la crisis entre medias). En este contexto, posiciona los casos de Madrid y Barcelona y evidencia, en este caso, qué pasa en sus núcleos históricos en cuanto a la sustitución de población y las expulsiones y en relación sobre todo a la turistificación y demás procesos correlativos. También se apuntan estas transformaciones en el resto de grandes ciudades españolas: Valencia, Bilbao, Zaragoza y Sevilla, ciudades con las que se establece la comparación para resaltar ambas ciudades como casos diferenciados y más llamativos. Metodológicamente, se recurre al análisis de datos secundarios cuantitativos (del INE, Idescat, Tinsa, Idealista, etc.) que permitan señalar indicios de los movimientos de expulsión desde el centro urbano; así como de un análisis discursivo a partir de datos primarios cualitativos con entrevistas a vecinos, comerciantes y responsables de la gestión municipal ${ }^{1}$ (FIG. 1) que ilustren el posicionamiento y percepciones de los vecinos en estas áreas turistificadas y expliquen cómo se ven condicionados sus movimientos centrífugos en el espacio urbano. Así mismo, se evidencia cómo el resto de tendencias constatadas en el centro, acompañan dichos procesos de desplazamiento poblacional.

\section{Las dinámicas que afectan a las grandes ciudades españolas: Madrid y Barcelona como casos paradigmáticos}

El turismo urbano crece un $7{ }^{\prime} 7 \%$ en 2017 , principalmente en los destinos internacionales (EUROPEAN Cities MARKETING, 2018). Entre los destinos urbanos europeos con más afluencia de turistas y pernoctaciones, destacan las ciudades españolas de Madrid y Barcelona, ocupando la posición quinta y sexta, respectivamente. Este notorio posicionamiento turístico encuentra su razón de ser en su constante crecimiento como destinos de cultura y de negocios. A gran distancia, se sitúan las ciudades de Sevilla y Valencia, Bilbao o Zaragoza. Por ello, tanto Barcelona como Madrid son aquellas con mayor

\footnotetext{
1 Para el caso de Barcelona, se recurre a entrevistas llevadas a cabo en el marco del Proyecto I+D Nuevas movilidades y reconfiguración sociorresidencial en la poscrisis: consecuencias
}

presencia de turistas respecto a dicha dinámica emergente, así como desigual entre unas y otras ciudades (FIG. 2). Las fuentes estadísticas de los respectivos organismos que se ocupan de la gestión turística, igualmente son indicativos de esta evolución desigual, puesto que su ritmo en la colección y tratamiento de datos, se encuentra acorde al interés del destino.

Estas dinámicas tienen un fuerte impacto sobre estas ciudades y así se denomina turistificación al proceso de transformación de la ciudad en un escenario monopolizado e hiperespecializado por actividades y servicios turísticos (LANFANT, 1994; CAZES, 1998; HARVEY, 2004; RICHARDS, 2016) que supone un fuerte impacto sobre el área de influencia y la ciudad en su totalidad. Se otorga una denominación a esta tendencia para diferenciarla de otras e individualizarla, responsabilizándola de muchos de los cambios que acontecen en los centros urbanos. Demográficamente, supone además una sobredensificación de estos espacios centrales y de oferta turística que va en perjuicio de la población tradicional residente, además de su paulatina expulsión y sustitución por otros pobladores y actividades que van organizando el cambio urbano, sobre todo en aquellas ciudades donde las tendencias son más intensas. Es así como los centros urbanos se ven apropiados por nuevos sectores que rentabilizan

\begin{tabular}{ll} 
Identificador & Representante \\
B1 & $\begin{array}{l}\text { Responsable técnica de } \\
\text { Promoción Económica, Comercio y } \\
\text { Turismo del Distrito de Ciutat Vella } \\
\text { de Barcelona }\end{array}$ \\
\hline B2 & $\begin{array}{l}\text { Representante de la Plataforma de } \\
\text { Vecinos del Raval }\end{array}$ \\
\hline B3 & Vecino del Raval \\
\hline B4 & Informante clave del Raval \\
\hline M1 & Vecina de Lavapiés \\
\hline M2 & $\begin{array}{l}\text { Informante clave de Lavapiés/ } \\
\text { Embajadores }\end{array}$ \\
\hline M3 & $\begin{array}{l}\text { Comerciante Lavapiés/ } \\
\text { Embajadores }\end{array}$ \\
\hline M4 & $\begin{array}{l}\text { Asociación tradicional Lavapiés/ } \\
\text { Embajadores }\end{array}$ \\
\hline
\end{tabular}

FIG. 1/ Relación de entrevistas Madrid y Barcelona.

Fuente: Varios estudios de los grupos GISMAT y MOVIURBES.

socioeconómicas y demográficas en las áreas urbanas españolas -MOVIURBES- (RTI2018-095667-B-I00). 


\subsection{0 .000}

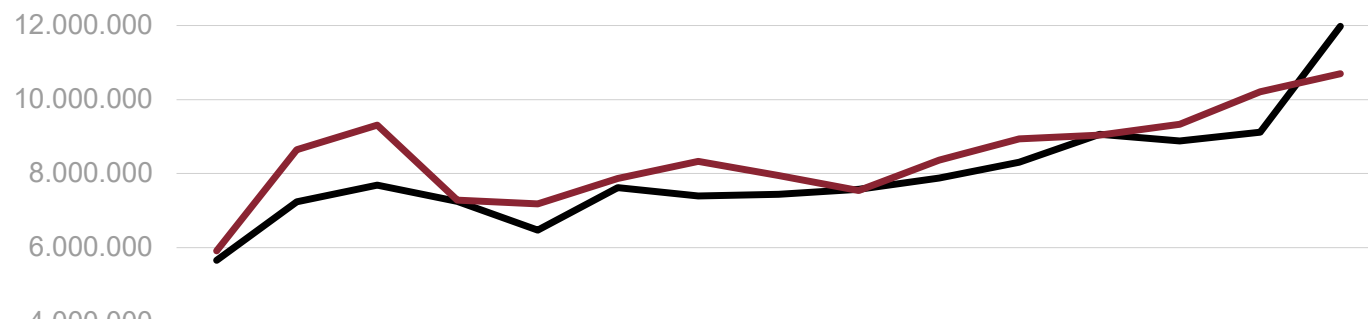

4.000 .000

2.000 .000

0

200520062007200820092010201120122013201420152016201720182019

$\longrightarrow$ Barcelona $\longrightarrow$ Madrid Sevilla Valencia $\longrightarrow$ Bilbao Zaragoza

FIG. 2/ Evolución del turismo internacional en las ciudades españolas (2005-2019).

Fuente: elaboración propia a partir de datos de Turisme de Barcelona, Visita Sevilla, Visit Valencia, Bilbao Turismo, Zaragoza Turismo y Madrid Destino.

su posición en la ciudad provocando la expulsión de otros.

En los casos de estudio analizados, se evidencia un crecimiento del alojamiento turístico, tanto reglado como no reglado que, en el caso de Madrid y Barcelona, es más intenso e impactante. Así en los espacios más atractivos para el turismo, los centros urbanos, sobre todo, está aumentando dramáticamente, tal y como indican los datos, tanto en número de establecimientos como de plazas. Para el caso de Barcelona, el alojamiento ofrece para el año 2019 un total de 73.173 plazas en hoteles y 58.583 en viviendas de uso turístico. Madrid manifiesta también esta tendencia creciente de plazas de acomodación turística reglada, como se puede ver en la FIG. 3, con un total de 88.268 plazas hoteleras y 22.937 en viviendas de uso turístico.

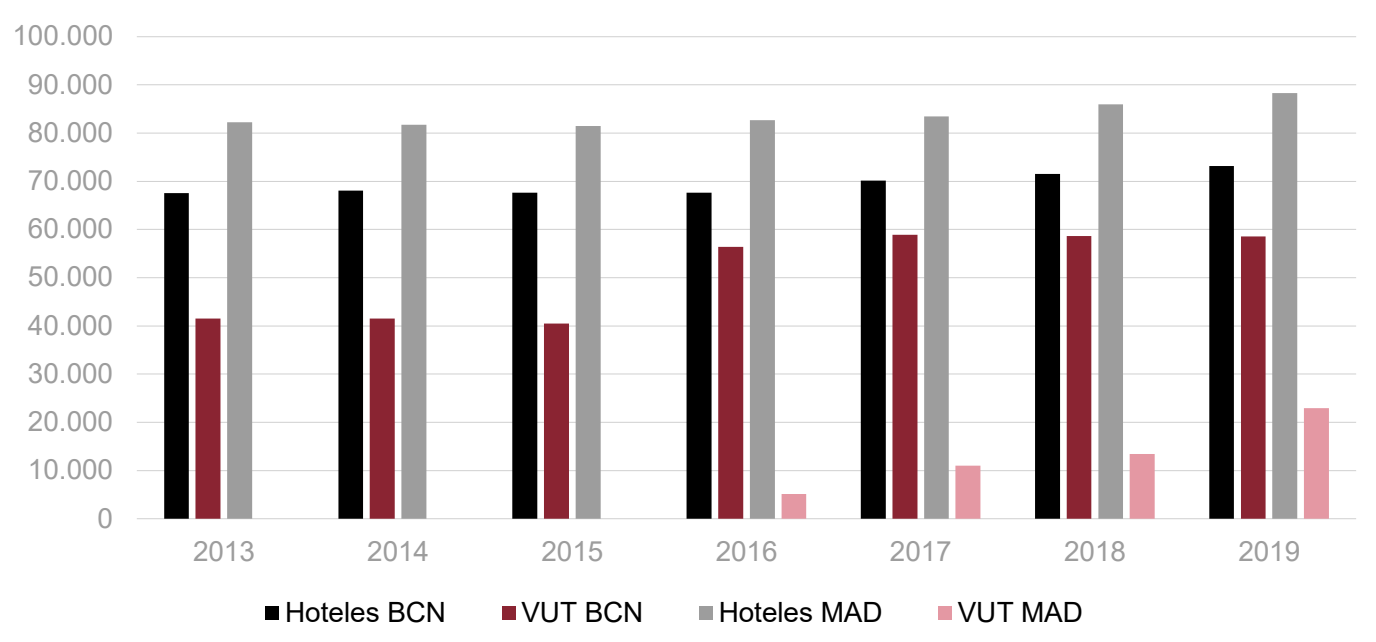

FIG. 3/ Evolución del número de plazas de alojamiento turístico reglado en Barcelona y Madrid: hoteles y viviendas de uso turístico (2013-2019).

Fuente: elaboración propia a partir de datos de Turisme de Barcelona y Subdirección General de Competitividad Turística. 
Evolución del precio de la vivienda en España

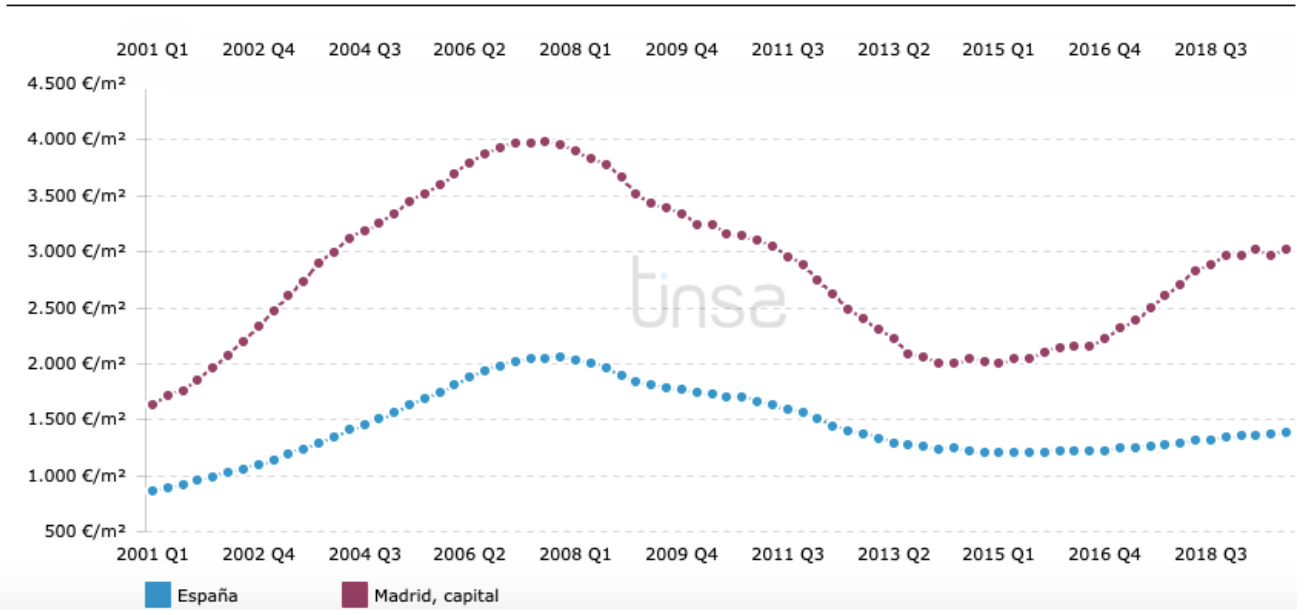

Evolución del precio de la vivienda en España

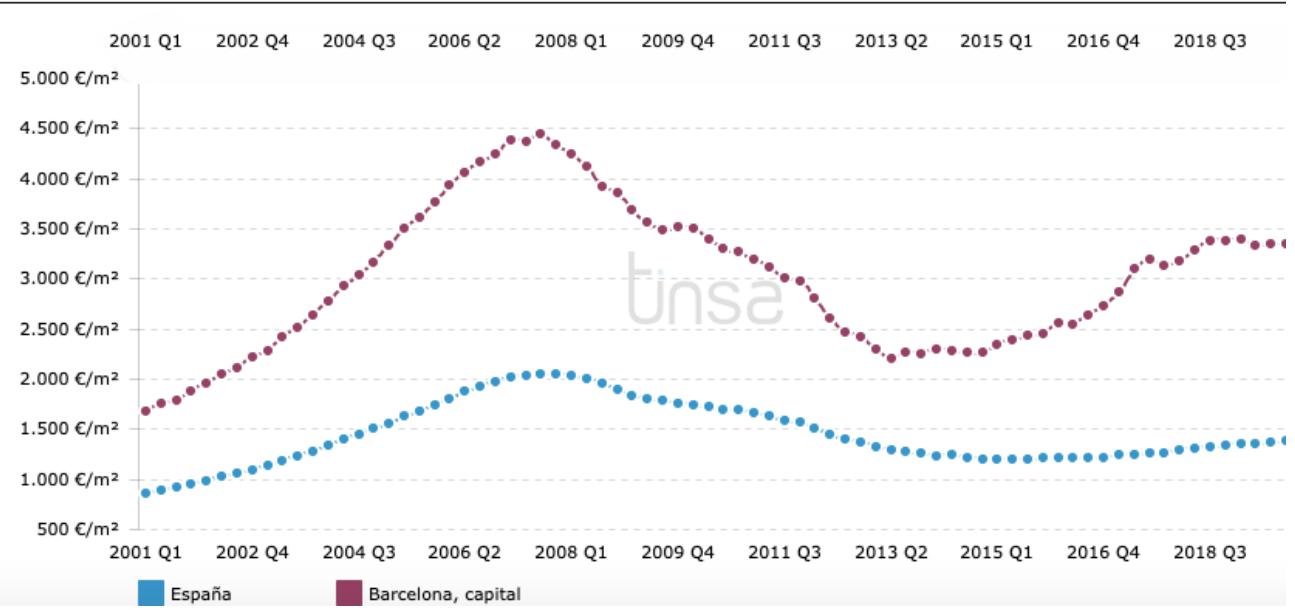

Evolución del precio de la vivienda en España

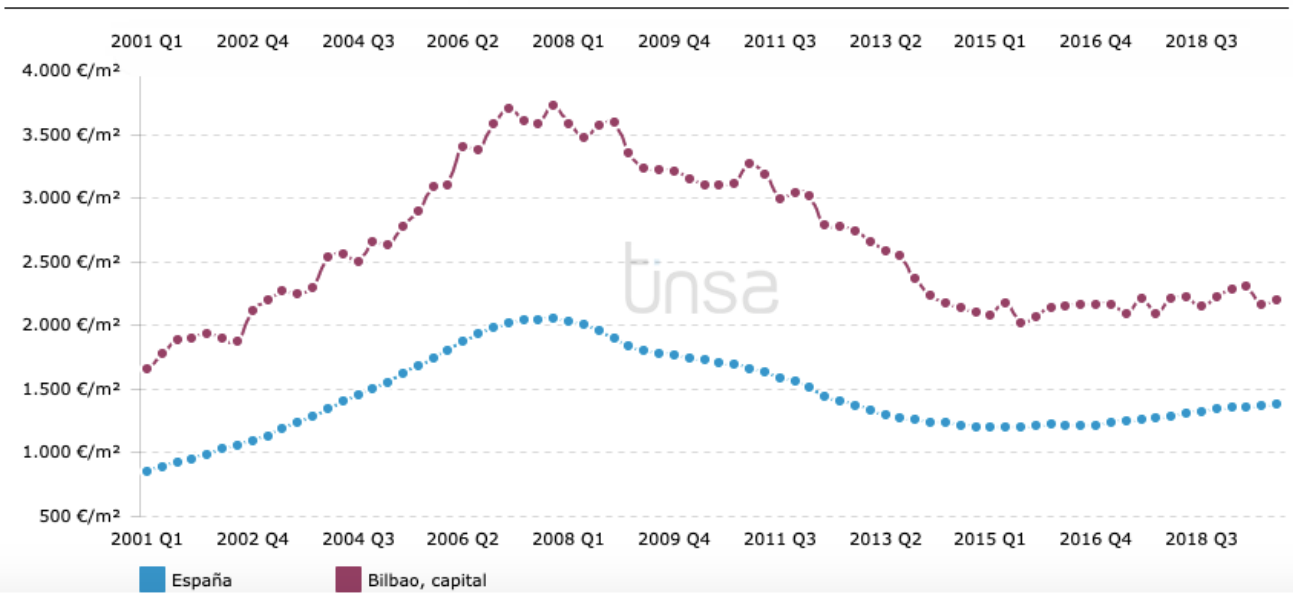


Evolución del precio de la vivienda en España

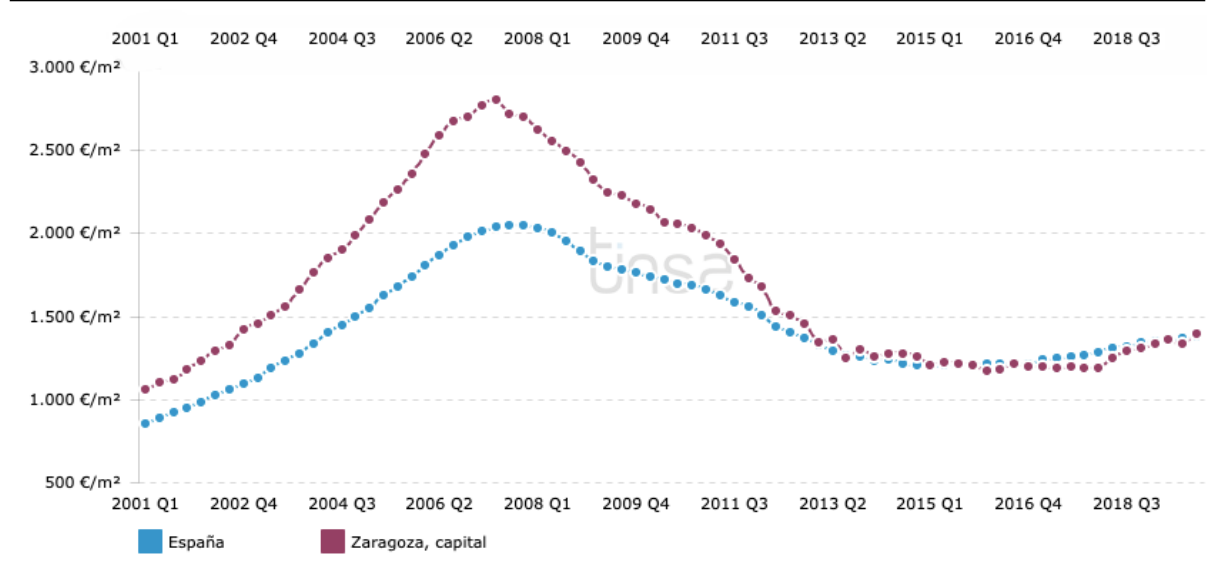

Evolución del precio de la vivienda en España

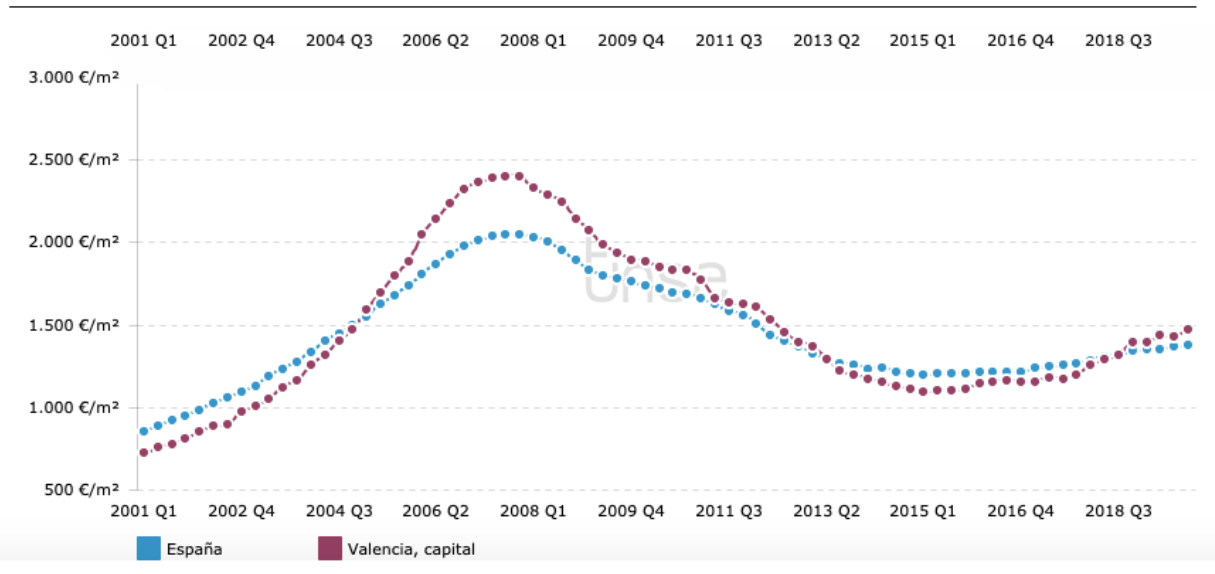

Evolución del precio de la vivienda en España

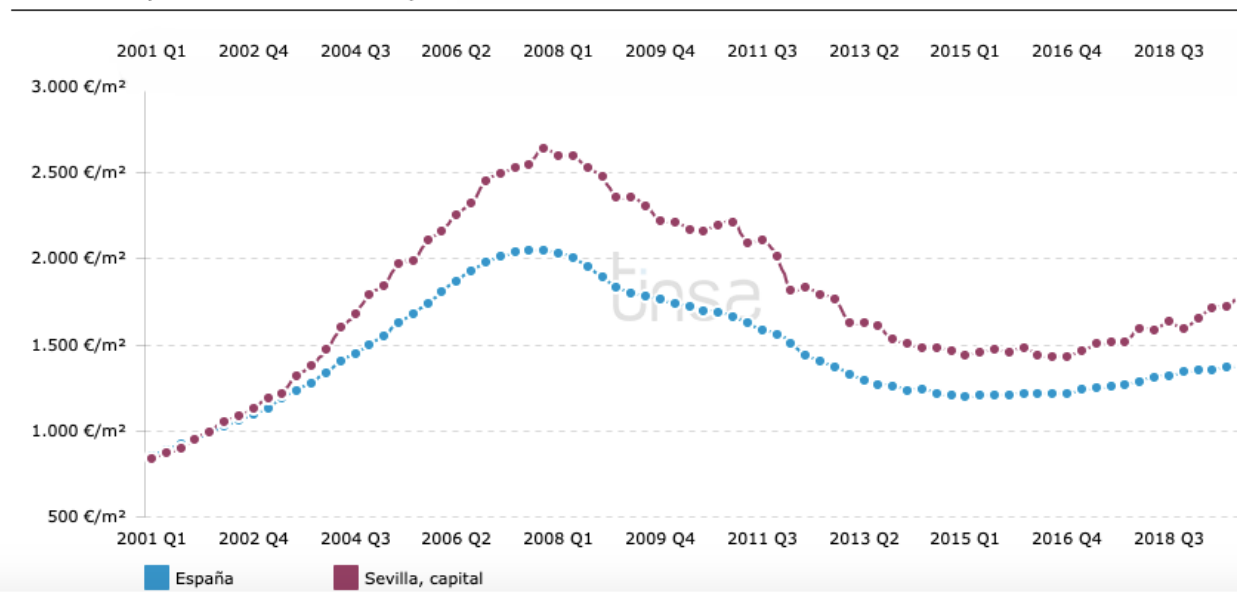

FIG. 4/ Evolución del precio de la vivienda en Madrid, Barcelona, Bilbao, Zaragoza, Valencia y Sevilla (2001- 2018).

Fuente: elaboración propia a partir de la página web de Tinsa. https://www.tinsa.es/ 
A este indicador, se debe añadir el incremento de los apartamentos turísticos que se comercializan a través de las plataformas de alojamiento colaborativo, como Airbnb principalmente. Muchos de ellos, al margen de la legalidad. Por ejemplo, en 2016 el portal insideairbnb.com (Analysis of "Entire homes/apartments" and "private rooms" in Barcelona, 2016) (INSIDE AIRBNB 2016) cifraba para Barcelona que un $78 \%$ del total de la oferta de la plataforma no disponía de licencia turística. Todo ello supone, pues, en el distrito centro, una notable reducción de la vivienda para uso residencial, así como su encarecimiento tanto por escasez como por cambio del público objetivo. Se produce así lo que se denomina airbnbificación (RICHARDS, 2016), así como una alteración de la vida y cultura locales, además de la pérdida de cohesión social (GALLAGHER, 2017; CócOLA, 2016; MARTIN \& al., 2018), la apropiación y congestión del espacio público.

Como consecuencia, esta tendencia de aprovechar la oportunidad de sacar rédito a una vivienda con inquilinos turísticos ha ocasionado cambios y movimientos residenciales de la población, así como una disminución del parque de vivienda de alquiler para usos residenciales y también el incremento de precios, tanto de compra como de alquiler (LOPEZ-GAY \& COCOLA GANT, 2016; NOVY, 2017; RuSSO \& ARIAS-SANS, 2017; QuAGLIERI \& ScARnAto, 2017). Así, se comprueba que el precio de la vivienda en estas dos ciudades es todavía mucho más elevado que en las seis grandes ciudades españolas de referencia que experimentan trayectorias diferenciadas. Madrid y Barcelona se posicionan como las de más elevado precio de la vivienda, muy por encima de la media de España durante toda la serie. Los gráficos de la FIG. 4 señalan el año 2013 como el punto de inflexión con el final de la tendencia descendente de los precios y el comienzo del nuevo ascenso.

\section{El impacto del turismo en el centro urbano de Madrid y Barcelona}

Como se ha señalado, la sobredensificación de vivienda turística, de hoteles, equipamientos de ocio y cultura, o de patrimonio es más evidente en los centros urbanos. Es por ello que estas dinámicas descritas más arriba tienen un efecto más intenso en estos espacios y especialmente sobre las áreas más vulnerables de dichos centros, cuando estas existen. Tanto los turistas como los espacios donde se alojan (hoteles, apartamentos, viviendas de uso turístico), están mayoritariamente localizados en el centro de ambas ciudades. Así se comprueba en los mapas de las guías turísticas de Madrid (Planos DE MADRID, 2020), donde la gran parte de los hoteles y las viviendas turísticas se localizan en el centro, como en muchas otras ciudades europeas. Así del total de las 127.031 plazas turísticas en 2019, la mayor parte procede de hoteles $(56 \%)$ y otra importante parte $(26 \%)$ de los apartamentos turísticos o viviendas de uso turístico. Según los datos del AyUNTAMIENTo DE MADRID (2016), la mayor parte de las plazas hoteleras se localiza en el centro $(28 \%)$, como también la mayor parte de los apartamentos turísticos (el $21 \%$ de los apartamentos turísticos y el $61 \%$ de las viviendas de uso turístico) y de estos, la mayor parte (25\%) en Embajadores y otra parte en Universidad $(21 \%)$, los dos barrios con menor nivel socioeconómico del centro como se evidencia a continuación. En el caso de Barcelona, del total de las 149.467 plazas turísticas en 2019, la mayor parte procede de hoteles $(48,9 \%)$, y otra importante $(39,7 \%)$, de apartamentos turísticos y viviendas de uso turístico. Según los datos del Ayuntamiento de Barcelona (2019), la mayor parte de las plazas se localizan en el Eixample, el distrito que configura el límite territorial del centro histórico de la ciudad condal. Ciutat Vella es el segundo distrito que concentra más plazas hoteleras $(26,4 \%)$, pensiones y hostales $(24,5 \%)$, apartamentos turísticos $(31,24 \%)$ y viviendas de uso turístico (5,5\%). De todas estas plazas turísticas regladas de Ciutat Vella, en el barrio del Raval se concentra el 11\% de hoteles, el $6 \%$ de pensiones y hostales, el $36 \%$ de apartamentos y el $0,5 \%$ de vivienda de uso turístico.

Esto es, que la mayor parte de la oferta turística total se localiza en los barrios del centro de ambas ciudades. En cuanto a la oferta de Airbnb en Madrid, esta se ha incrementado exponencialmente. Así desde las 217 ofertas de 2012 se ha llegado a 21.564 en 2019 (según datos del portal INSIDE AIRBNB 2020). De estas plazas, la mayoría $(51,5 \%)$ tenía su localización en el distrito centro de la ciudad y de ellas, una gran parte en Embajadores (28\%). En el caso de Barcelona, el porcentaje de plazas ofertadas en Ciutat Vella es del 22,4\% del total (18.302), muy concentradas en EI Raval. Por otro lado, el caso de Barcelona es todavía más intensivo que el de Madrid y así se comprueba en la presión de la vivienda turística sobre la residencial. En 2015 , el porcentaje de vivienda de uso turístico (VUT) sobre el total de viviendas del centro es de $18 \%$ en Ciutat Vella en Barcelona frente al 9\% en Madrid centro (Ayuntamiento de Madrid, 2016). La FIG. 5 muestra esta evolución intensa del denominado alojamiento colaborativo. 


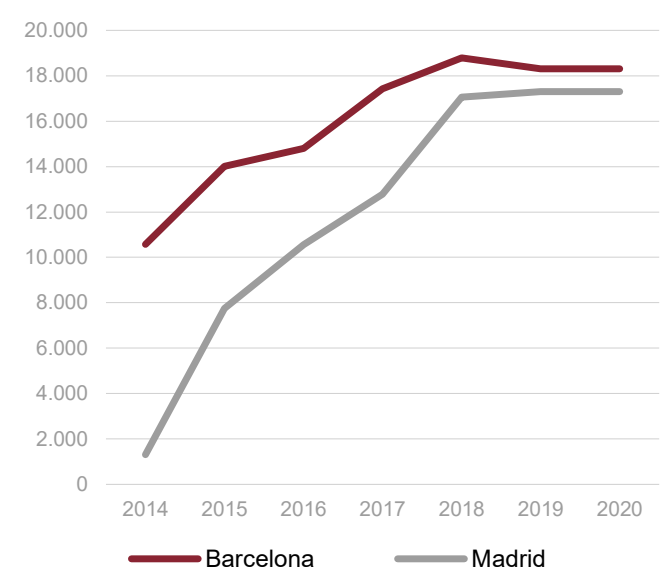

FIG. 5/ Evolución de los apartamentos listados en Madrid y Barcelona en Airbnb (2014-20).

Fuente: elaboración propia a partir de datos de Inside-Airbnb 2020

Por lo general y a diferencia de las ciudades americanas, el centro urbano de las ciudades europeas cuenta con un nivel socioeconómico por encima de la media de la ciudad, pero a veces quedan algunas áreas deprimidas. En un marco de auge de la turistificación e interés sobre el centro, sobre todo estas áreas se convierten así en espacios de oportunidad para inversores, capital, etc. por estar bien localizadas y ofrecer gaps de renta por su bajo valor previo. Es precisamente en estos donde se localiza una gran parte de las viviendas turísticas y que han experimentado también notables alzas de precios impactando en el precio medio de la zona. Son así mismo zonas de concentración de población vulnerable (clases populares, inmigrantes) de vivienda en alquiler y de comercio tradicional. Los centros analizados de ambas ciudades, concretamente los barrios del Raval en Barcelona y Embajadores en Madrid, se caracterizan por el menor nivel de renta del distrito, como se observa en la FIG. 6 (ver las manchas más claras sobre el mapa de la renta por persona, según datos del INE, 2016). Ambos barrios dibujan islas más vulnerables en el centro de la ciudad (señaladas en rojo).

En este panorama de alza de precios de vivienda y tras la crisis 2008-09, la presión sobre los hogares que todavía residen en estos dos barrios, se hace más intensa y en esta situación, los hogares vulnerables son más frágiles. Según los datos de la OCDE (mencionado en SALVI DEL PERo, 2016), el costo de la vivienda constituye la partida individual de gasto más alta del presupuesto familiar y representa una gran carga financiera para las familias de bajos ingresos, como en el caso de España, en el que más de la mitad de las familias en el quintil más bajo de la distribución de ingresos, gastaba más de $40 \%$ de su ingreso disponible en alquiler. Según el Fondo Monetario Internacional (FMI), España es el país de la OCDE (el colectivo de países más ricos del mundo) que peor relación tiene (después de Polonia) entre los precios de la vivienda (incluyendo el alquiler) y los ingresos familiares. Según el Global Housing Watch del FMI (2017), en España más del 40\% (en Barcelona el $42,7 \%$ ) de los ingresos familiares se dedican a pagar el alquiler, porcentajes mucho más altos, por ejemplo, que en Francia, Suiza o Alemania donde tales porcentajes son del $16,5 \%$, el $18,2 \%$ y el $23 \%$ respectivamente. Además, el $78,2 \%$ de las familias españolas (EUROSTAT, 2017) tiene vivienda en propiedad. Y a ello debe añadirse que los salarios no se han incrementado. Desde 1998 a 2011, los salarios en España registran un estancamiento que se intensifica a partir de 2012 y hasta hoy día, puesto que a pesar de que la productividad se recupera, los salarios descienden el 4'4\% (INE, 2020 , datos en línea sobre mercado laboral). Si además tenemos en cuenta los incrementos de los precios, se calcula que el poder adquisitivo de los trabajadores se ha reducido en un $10 \%$ de media.

$Y$ es que los precios de la vivienda en ambos distritos han ido creciendo de manera considerable, tanto en propiedad como en alquiler, como se ve en los gráficos de la FIG. 7. En el distrito centro de Madrid, el precio de la vivienda en alquiler ha pasado primeramente de 18 euros $/ \mathrm{m}^{2}$ en 2008 a 13,6 en 2013, tras la crisis, para ir paulatina y progresivamente elevándose hasta 19,4 euros $/ \mathrm{m}^{2}$ en 2020 . El barrio de Embajadores era uno de los de menor precio, pero ha ido elevándose así mismo progresivamente. En la actualidad (2020), se sitúa en 19,2 euros $/ \mathrm{m}^{2}$ muy cerca de la media del distrito $\left(19,4\right.$ euros $\left./ \mathrm{m}^{2}\right)$ (según datos de la inmobiliaria Idealista, https://www.idealista.com/ sala-de-prensa/informes-precio-vivienda/alquiler/madrid-comunidad/madrid-provincia/madrid/ centro/) y cuando además anteriormente la diferencia con la media del distrito era mayor y así en la actualidad las diferencias se aminoran en favor de Embajadores. Paralelamente, en Barcelona en Ciutat Vella en la actualidad el precio es de 19,4 euros $/ \mathrm{m}^{2}$, superior a la media de la ciudad (16,8 en enero 2020); y en el Raval, es algo inferior al distrito, pero también sobre la media de la ciudad (18,3 euros $\left./ \mathrm{m}^{2}\right)$. Anteriormente en 2009, a diferencia de Madrid, era ya elevado en Ciutat Vella $(15,8)$ para ir descendiendo hasta 2013 y posteriormente volver a elevarse hasta la actualidad (datos de Idealista, 
https://www.idealista.com/sala-de-prensa/informes-precio-vivienda/alquiler/cataluna/barcelona-provincia/barcelona/ciutat-vella/). Así, se comprueba que el precio en los distritos centro de ambas ciudades está muy por encima de la media de la ciudad y que, dentro de estos, los dos barrios afectados, Embajadores y el Raval, tienen precios por debajo de la media del distrito central, pero que también son elevados y se han ido elevando en el periodo analizado provocando cambios internos. Esto es, que vivir en Embajadores y el Raval cada día se ha ido haciendo más caro tanto respecto a la compra de propiedad como sobre todo al alquiler, impactando así sobre los colectivos más vulnerables.

Pero como se ha comprobado, no solo se ha incrementado la oferta turística y se han elevado los precios de la vivienda, sino que también han cambiado los entornos cotidianos de estos dos barrios. Eso es, en ambos barrios no solo ha cambiado lo físico sino también lo cultural, lo simbólico y así lo discursivo. Nos referimos al cambio de estilo de vida y ambiente predominante en el centro, que provoca así mismo la expulsión simbólica de los actuales residentes

Renta por persona (€)

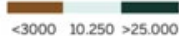

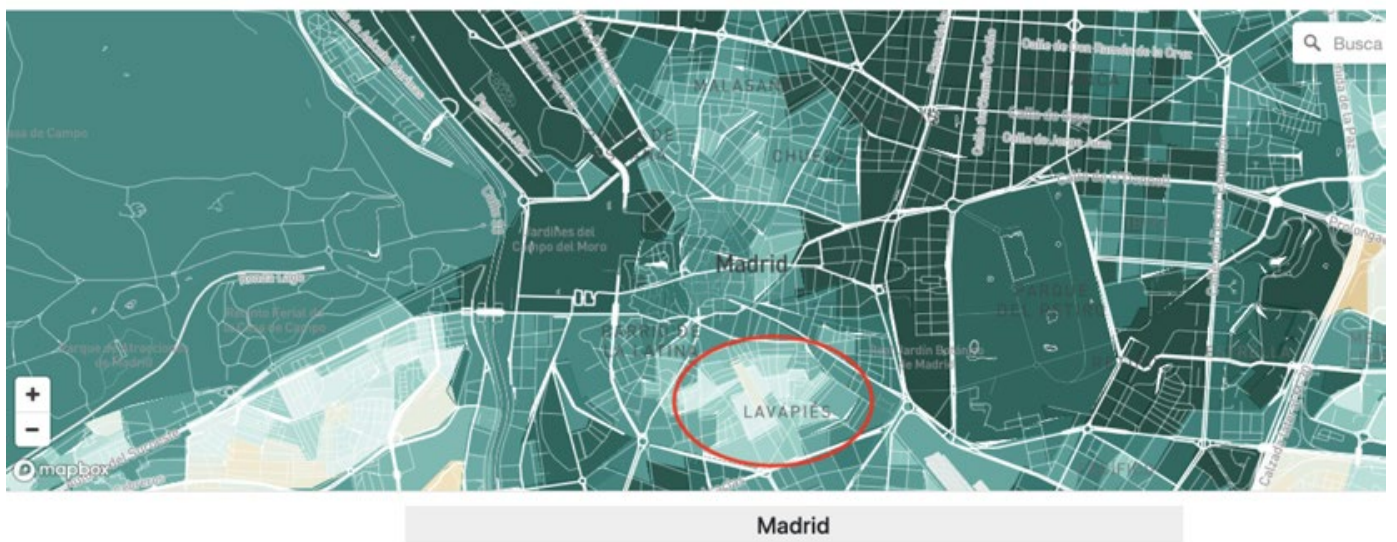

Renta por persona (€)

$<3000 \quad 10.250>25.000$

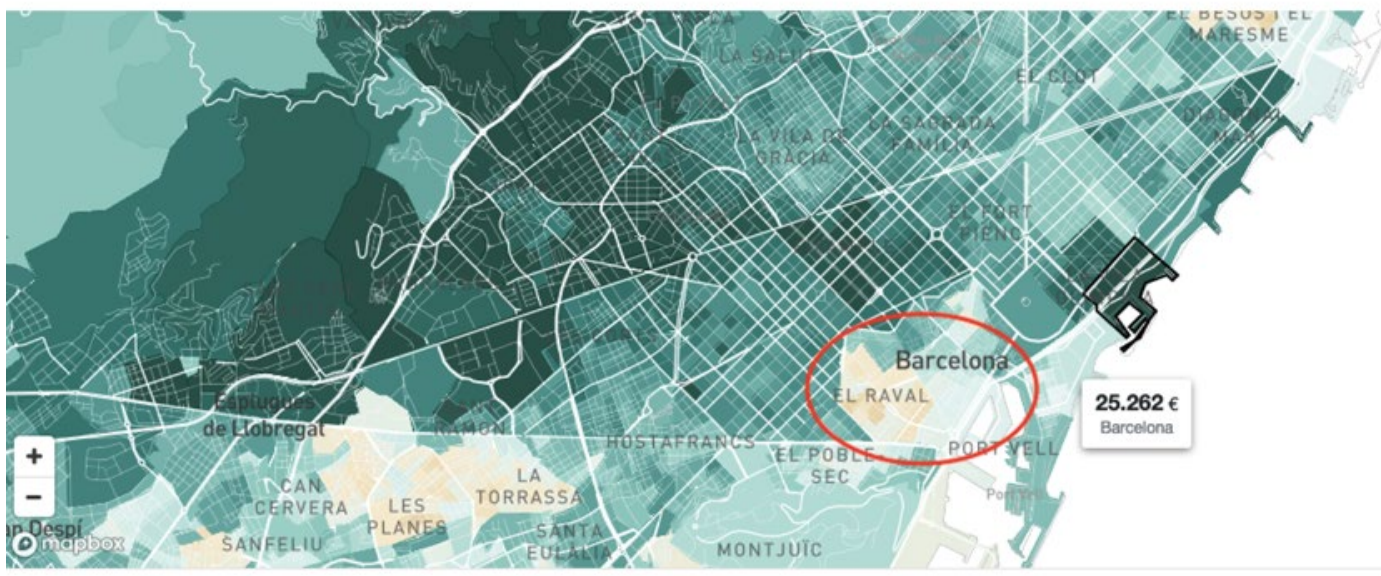

Barcelona

FIG. 6/ Mapas de renta por persona: Madrid y Barcelona (zoom sobre mapa de España). 2016.

Fuente: INE. Nuevos datos de renta por secciones censales. Renta 2016. 


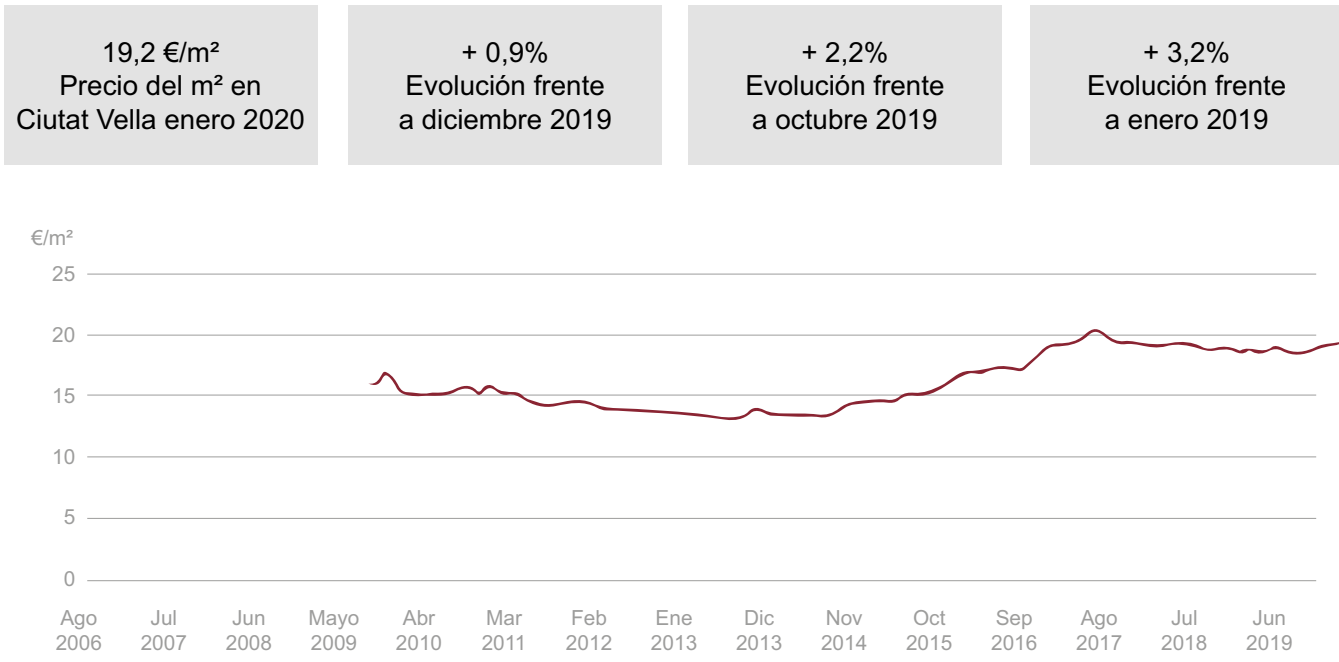

FIG. 7A/ Barcelona: Ciutat Vella, evolución del precio de vivienda en alquiler.

Fuente: datos de la pagina web de Idealista, 2020.

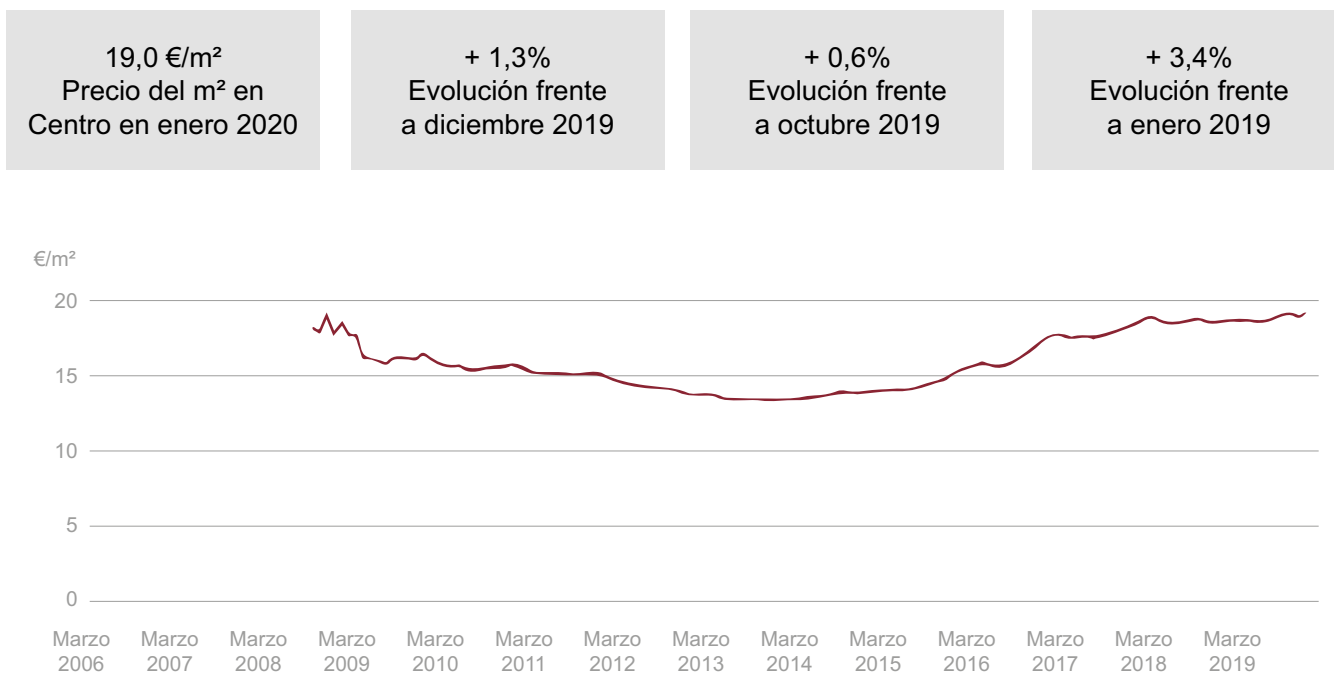

FIG. 7B/ Madrid: Distrito Centro, evolución del precio de vivienda en alquiler.

Fuente: datos de la pagina web de Idealista, 2020.

que acompaña la expulsión demográfica. Esta tendencia homogeneizadora responde a la reiterada y constante búsqueda de autenticidad por parte de la demanda turística, un comportamiento denominado por los académicos New Urban Tourism (FüLLER \& MıCHEL, 2014). Según MAITLAND (2010), los turistas buscan en la ciudad disfrutar de los recursos patrimoniales tangibles (museos y monumentos), pero también de los intangibles (estilo de vida, imagen y creatividad). El nuevo paradigma de turismo urbano consiste en "ser" más que en "hacer", ser como un local (mientras se viaja) atraído por los lugares frecuentados por los verdaderos lugareños, en búsqueda de lo auténtico, de lo genuino. Esto es, que en estos espacios todavía 
persiste la heterogeneidad propia de los centros urbanos, pero que de manera intensa y rápida se va transformando en otra realidad urbana más homogénea. Así se evidencian las viejas formas autóctonas de vida, pero paralelamente se asiste a una homogeneización del escenario (DELGADO, 2003), mediante la banalización, disneyficación y estandarización de este que atrae a su vez a otros sectores reforzándolo. Incluso se busca caracterizarlo como espacio de más glamour y encanto cultural, que es a su vez similar a otros espacios, a través de formas de "artistización" del espacio urbano. Estos cambios impactan principalmente en los sectores vulnerables del centro de la ciudad, afectando a su derecho a la ciudad y poniendo de relieve las dos caras del barrio:

"Uf, es que Lavapiés es muy complejo, Lavapiés tiene una cara de día, y tiene otra cara de noche, y a la madrugada tiene otra cara totalmente diferente... por lo menos el Lavapiés de día es el Lavapiés de los curritos, es el Lavapiés de los compañeros que trabajan en el top manta... es el Lavapiés de la plaza de Lavapiés... y no voy a decir nacionalidades, porque aquí no viene a cuento, de gente traficando con drogas... pero es gente que a final de cuentas son curritos... (...) aquí en Lavapiés, bueno, hay gente muy mayor, hay una población de gente mayor que es muy grande...(...) pues es gente que recurre al top manta, a trabajos esporádicos... hay mucha gente de aquí, gente joven que trabaja en la limpieza... cuando te hablo de gente joven, yo tengo 40 , casi 40 años, yo todavía me considero muy joven, entonces me equilibro dentro de eso... trabajos que... que no es que sean desagradecidos ni mucho menos, pero, yo tengo un amigo que es sastre, él es de Bangladesh, y tiene que vender cerveza por la noche...(...)" (ENTREVISTA M2).

Este cambio de ambiente puede ser también evidenciado a través de la constatación de su conversión en espacios de compras, consumo, diversión, ocio, glamour, y sobre todo de sobredensificación, como lo demuestra el hecho de que en ellas se realizan la mayor parte de las transacciones comerciales del total de la ciudad, las cuales proceden principalmente del turismo (BBVA, 2020). Un escenario urbano de mayor movilidad y consumo reemplaza al carácter de barrio residencial previo.

Como consecuencia, se evidencia un proceso de desposesión simbólica de los edificios y espacios de sociabilidad de los residentes tradicionales (BENACH, 2016) al comprobar que sus escenarios cotidianos han cambiado y que, de este modo, se ven expulsados simbólica y físicamente de ellos. Esto es, que la turistificación conlleva efectos físicos y económicos, pero también culturales y simbólicos. Es algo que también puede evidenciarse en el discurso de los vecinos de los barrios:

\begin{abstract}
"Más allá de las estadísticas, la mayoría que vivimos en el Raval son extranjeros europeos, franceses, italianos que se pueden pagar lo que cuesta un piso (900 euros de alquiler al mes) y que algunos lo alquilan a turistas...pero gente de aquí, de siempre, queda poca, muy poca...un policía jubilado con su mujer, ... y claro, hay mucha inmigración de gente de Europa, del Norte, hay muchos inmigrantes también marroquíes y de Asia, y tienen aquí su comunidad, pero estos están en Raval Sud...en Raval Norte no... Aquí solo población europea y aquí si puedes ver un desplazamiento de la gente ....al Sur, con sus comunidades de filipinos, asiáticos ...muy arraigados... Me gusta el barrio por sus contrastes, su variedad de personas, algunas pasantes, otros se quedan...pero tiene mucha oferta cultural, vida asociativa y mucha solidaridad con distintas causas y países, con mucha preocupación social... pero claro hay segregación..." (ENTREVISTA B4).

“... que todo este boom que están dando al barrio de Embajadores como el barrio más cool, no sé qué, no sé cuánto... al final perjudica a los vecinos y vecinas que vivimos aquí, es decir, porque aquí lo que están haciendo es intentar echarnos del barrio para seguir especulando con el tema de las viviendas y todo el tema ese (...) La calle Argumosa en verano es una terraza, empieza en la plaza de Lavapiés y acaba donde el Reina Sofía casi. De gente pues que, hasta las cuatro de la mañana y el vecino, vecina, pues está molesto. (...) aquí la gente que está empezando a comprar piso, es gente joven, nivel medio-alto, mucho profesional y que puede permitirse el lujo de pagar mil, mil y pico de euros por alquiler (4 M3).
\end{abstract}

\section{Expulsiones en los centros urbanos de Madrid y Barcelona}

De este modo y como se ha constatado, todos estos procesos descritos han supuesto una transformación de usos a raíz de una revalorización de los inmuebles o un encarecimiento de los precios de compra y/o alquiler y también un cambio en el estilo de vida en el centro urbano. Ello conlleva dos procesos complementarios paralelos: la invasión de los turistas y la consiguiente expulsión de los vecinos más vulnerables. El dato llamativo es que la población del centro de Madrid y Barcelona ha ido decreciendo paulatinamente, y así el centro cada vez cuenta con menos vecinos. Ciutat Vella, en 2004 tenía 8.173 habitantes $(10 \%$ del total de Barcelona), en 2011 había crecido la población 
a $13.144(12 \%)$, pero en 2018 había descendido de nuevo a $9.411(10,18 \%)$. El caso de Madrid es también similar. Si en 2004 Embajadores contaba con 50.940, en 2011 era de algo menos, 49.828, y en 2018 era menor (44.630). Así, estos barrios experimentaban una tendencia decreciente y representaban una menor proporción de la población total entre 2004 y 2018 , como se observa en la FIG. 8.

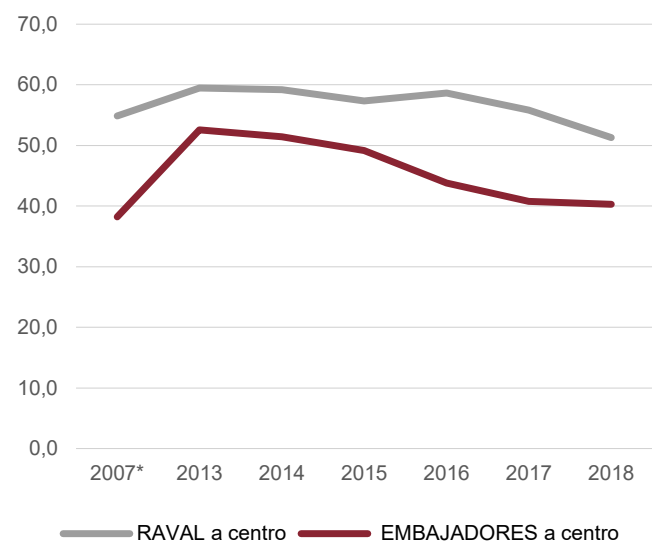

FIG. 8/ Evolución de porcentaje de vecinos del Raval y Embajadores que cambia de domicilio y se queda en el centro.

Fuente: elaboración propia a partir de los datos de Munimadrid y del AYUNTAMIENTO DE BARCELONA.

Pero al mismo tiempo que los centros pierden población, cambian su composición interna; esto es, que, aunque sean menos por un lado, por otro, ya no son los mismos que estaban; es decir, que se evidencian cambios internos. $Y$ de este modo, en el centro, coexiste la ciudad de los inmigrantes y la población envejecida junto a la ciudad cool de los hipsters, los gentries, los turistas, los estudiantes, los extranjeros, pero con un cierto nivel socioeconómico, dando lugar al mosaico urbano, a la ciudad de los contrastes. Como ya se ha comprobado, las últimas tendencias en años recientes han ido en la línea de un desarrollo intenso del alojamiento turístico, sobre todo del denominado alojamiento horizontal, dentro de un modelo de turismo colaborativo tanto puro como híbrido (Russo, 2015), en el que la plataforma Airbnb tiene un notable protagonismo. Este tipo de oferta actúa a través de portales web dedicados al alquiler de viviendas para uso turístico, lo que provoca un desequilibrio de su uso entre residentes y visitantes:

"Es un barrio complejo, diverso, dinámico, conflictivo... sobre todo degradado, sucio, hay varios ravales con diferentes tipos de visitantes y residentes... hay cada vez más turistas que penetran en estos espacios menos glamurosos... Los turistas no son ningún problema. Hay turistas que van y vienen en bici, con sus maletas, pero su presencia no afecta el día a día. La prostitución está bastante concentrada...este es el problema...para mí el tema es este, abordar la prostitución" (ENTREVISTA B4).

Por lo tanto, lo que ha supuesto es que, a través del encarecimiento y el cambio cotidiano de la vida del barrio, se constate la expulsión de los vecinos más vulnerables provocando un menor número de residentes. Sin embargo, probablemente también de sectores más acomodados que ante las incomodidades del centro buscan otros enclaves. Así lo ponen de manifiesto los movimientos de los vecinos de ambos barrios que, ante el alza de precios o las molestias ocasionadas por la sobredensificación, se ven obligados a abandonarlo. En el barrio del Raval, por ejemplo, se ven obligados a abandonar su comunidad de toda la vida porque los precios de las viviendas resultan imposibles de comprar, y en caso de que haya opción de alquiler, los propietarios prefieren a los turistas antes que a los residentes, a pesar de que estos alquilen la vivienda por un tiempo ilimitado. En Madrid sucede algo similar donde muchos hogares han de salir del centro hacia otros espacios donde encontrar vivienda más asequible y así lo evidencian los vecinos:

"...que es un problema que no te va a sorprender, es el problema es que se le está echando a la gente del barrio (...) Se está echando a la gente del barrio con la subida de alquileres. (...) pero lo que sí que está pasando, te lo digo porque me lo comentan vecinos y gente, vamos, aquí en el mercado hay tres personas o tres parejas que se van a tener que ir del barrio porque les vence el contrato y les dicen que fuera; o eso o que le dicen "mira, quiero 400 euros más al mes" y 400 más los 400 que pagabas o más los 1000 que pagabas, entonces dices "mira, no" qué puedo hacer, me tengo que ir. O sea, el problema es eso, el problema que veo ahora mismo es que se está echando pues a gente que... no es lo mismo que echen a gente de 40 años, 30-40 años que es una putada también... que echen a gente de 60 (...) Es que está afectando a mucha gente que de repente... el propietario del inmueble dice "Uh, aquí estoy haciendo el gilipollas con vosotros" eso yo creo que ahora mismo es el problema así más serio que hay en Lavapiés (...) Si, si, la vivienda que está siendo escandaloso." (...) que hay gente que sí que se está yendo, ahí sí que les afectara el problema, aunque yo sea el propietario de mi casa, si mi vecino que es alquilado se tiene que ir porque le suben el alquiler, pues ya me estoy yendo (...) imagino que lo que harán 
será echar a todos los inmigrantes y buscar turistas que son más molones, que son gente aseada, blanca y que no... (ENTREVISTA M2).

La explotación de datos de cambios de domicilio internos dentro del municipio permite constatar que los vecinos de estos dos barrios pueden ser clasificados como barrios de bajo nivel socioeconómico en el resto del distrito, y que comienzan a salir de sus barrios por diversos motivos hacia distritos considerados de alto y bajo nivel según el indicador de precio de la vivienda (FIG. 9)2. Así, se comprueba que los que salen de Embajadores concretamente son 5.160 en 2004, 5.701 en 2013, y van descendiendo hasta 4.134 en 2018 , esto es, que cada vez salen menos. De ellos, se quedan en el Centro cada vez una menor proporción (52\% en 2013 y $40 \%$ en 2018); en definitiva, los vecinos de Embajadores cada vez salen más a otros distritos de fuera del Centro. De los que salen, se van en proporciones más o menos similares hacia distritos de bajo y alto nivel, aunque destaca como más alta la proporción de la movilidad hacia los distritos de bajo nivel. Ello probablemente debido a que algunos salen por

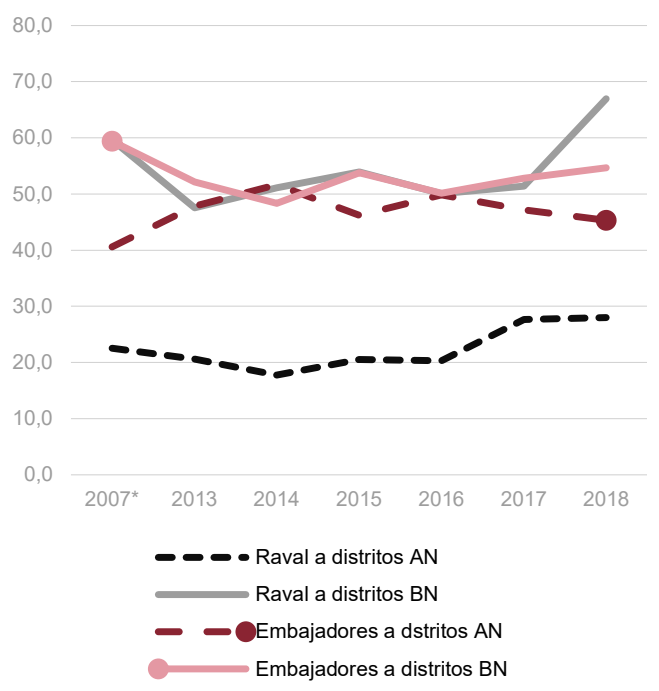

FIG. 9/ Evolución de cambios de domicilio del Raval y Embajadores hacia distritos según precio de vivienda (Alto y Bajo Nivel). 2007-2018.

Fuente: elaboración propia EVR AYUNTAMIENTO DE BARCELONA * dato de 2007 en Barcelona y de 2004 en Madrid.

\footnotetext{
2 Se han clasificado los distritos de Madrid y Barcelona según el precio medio de la vivienda para poderlos clasificar en
} dos tipos: alto y bajo nivel según se coloquen sobre o bajo saturación, incomodidad, por mejora de vivienda, u otros motivos, destacando que los que más se mueven es por obligación, por subida de alquileres, por desahucio, etc. como se venía señalando. Estos últimos, cada vez en mayor proporción como se señalaba en la hipótesis, lo cual permite aventurar que en lo hacen búsqueda de vivienda asequible respecto del alza de precios del barrio de origen.

En Barcelona, sucede lo mismo, pero con matices. Aquí el centro, Ciutat Vella, es un espacio más reducido que el centro de Madrid y, por tanto, más saturado y con menor capacidad de expansión turística. En él los residentes que cambian de domicilio tienden a ir a distritos de bajo nivel de precios de la vivienda tal vez por dicha saturación, así como por una antelación en las tendencias de Barcelona respecto de Madrid. Del barrio del Raval, salen cada vez menos residentes, en general como en Embajadores, y además se quedan menos en el distrito centro; y van sobre todo a barrios de bajo nivel, de manera más o menos constante, durante este periodo. Esto es, que en el Raval los más vulnerables son presumiblemente los que salen desde 2007.

Así es este mismo periodo el que correlaciona con el número de desahucios que afectan sobre todo a la población más vulnerable, y más en las dos ciudades analizadas. Considerando las seis ciudades de referencia, Madrid y Barcelona son, una vez más, las provincias con mayor número de desahucios. Sin embargo, todas ellas experimentan una tendencia descendente entre 2013 (desde el comienzo de la serie disponible) y 2018. En referencia a este dato, el caso de Madrid en cuanto a la situación del alquiler, es más grave que en Barcelona. En general, en ambas ciudades son mucho más numerosos los desahucios de alquiler que los hipotecarios (FIG. 10). Madrid y Barcelona nuevamente presentan datos muy diferentes y así, si bien es menor el número total de desahucios de Barcelona que el de Madrid, también hay que diferenciar que el número de desahucios hipotecarios es mucho más elevado en Madrid que en Barcelona, y que el de alquiler es, además de más elevado, más o menos similar en ambas ciudades. Sin embargo y en cuanto al alquiler, mientras que Barcelona sigue una trayectoria descendente, Madrid en los últimos años experimenta una trayectoria ascendente, como Zaragoza, Sevilla y Bilbao.

la media del municipio. De este modo se pueden clasificar los barrios entre los de alto y bajo nivel, tomando como referencia el precio de la vivienda. 


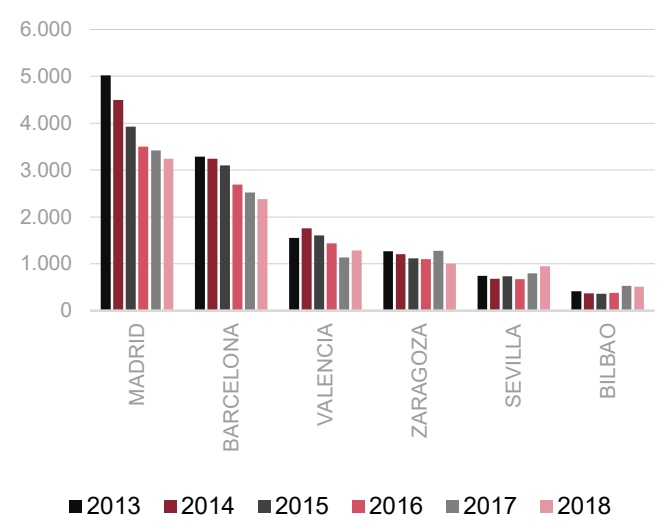

Número de desahucios total en las grandes ciudades españolas (2013-2018).

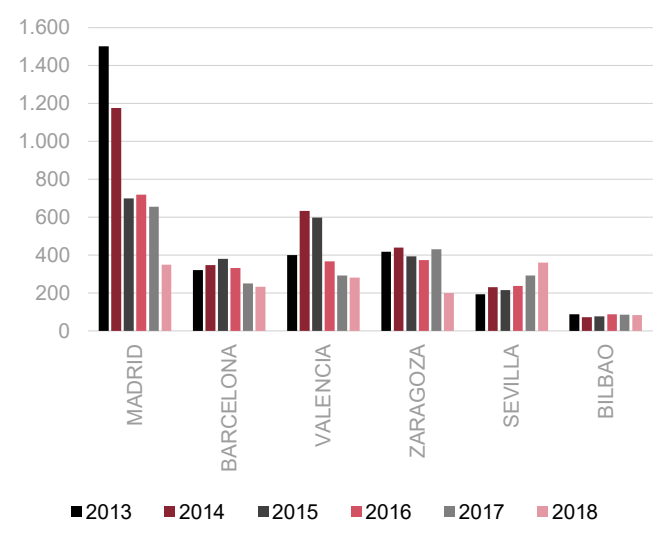

Número de desahucios hipotecarios en las grandes ciudades españolas (2013-2018).

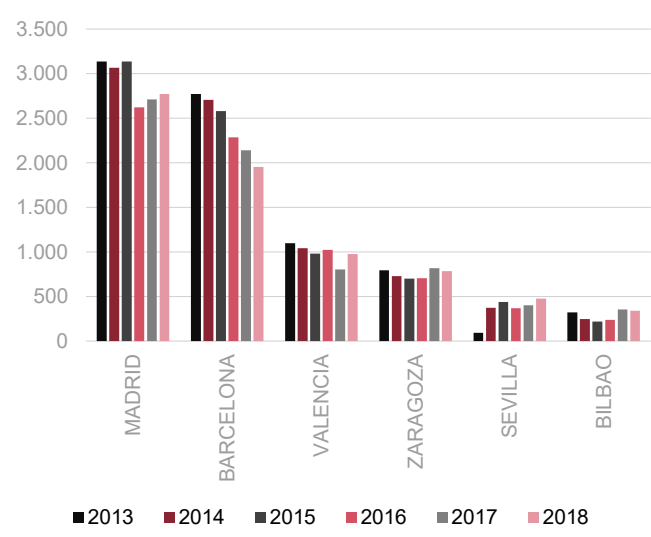

Número de desahucios alquiler en las grandes ciudades españolas (2013-2018).

FIG. 10/ Evolución total desahucios (hipotecarios y de alquiler) en las grandes ciudades españolas (2013-2018).

Fuente: elaboración propia a partir de datos de lanzamientos de CGPJ.
Otros estudios refuerzan esta idea y así según el último informe FoESSA (2019), en Madrid los hogares excluidos residen en vivienda de alquiler en un porcentaje del $48 \%$, mientras que entre los integrados la presencia del alquiler es menor $(30 \%)$. En Cataluña, dichos porcentajes son del $55 \%$ y del $27 \%$ respectivamente (FoESSA, 2019). Esto es, que es más probable ser excluido si se vive en alquiler que en propiedad. Los dos barrios analizados son barrios de alta concentración de vivienda en alquiler. Sin embargo, lo que se evidencia es que antes de abandonar la vivienda, o dejar de pagarla, los hogares vulnerables recurren a diferentes estrategias de contención (reducir gastos de alimentación, energía, ocio, etc.) (PROYECTO VUPACI, 201518; FoessA, 2019; ProviviendA, 2018) lo cual permite aventurar que en la vivienda pueden diferenciarse situaciones de vulnerabilidad que chocan con los cambios de nivel socioeconómico del barrio donde se radicaban que eran de mejora considerable. En este sentido, el índice de pobreza en Madrid desde 2007 se ha ido incrementando pasando de 16\% en 2007 a 20,6\% en 2017 (Informe CCOO, 2018). En Cataluña el índice es del 19\% en 2017.

\section{Procesos paralelos de cambio urbano que refuerzan la tendencia subyacente}

Pero todo este proceso de expulsión de vecinos desde estos barrios no es solamente consecuencia de la turistificación sino que existen una serie de procesos que lo complementan y acompañan, y que responden a una lógica de fondo, incentivando así mismo el proceso de elevación de los precios de la vivienda tanto en propiedad como en alquiler. Entre ellos, la estudentificación, la gentrificación, la financiarización y la trendificación. Todos ellos son señalados por los vecinos de ambas ciudades como procesos que han provocado el cambio urbano en el barrio. Aparecen también identificados en su discurso:

Gentrificación. De este modo, como se ha visto, estos incrementos de los valores de las propiedades y de los precios de alquiler y compra, y la dificultad de acceso a la vivienda comportan el desplazamiento de muchas familias y mayor inestabilidad residencial (MódENES, 2019). Como constatan BAYONA-I-CARRASCO \& PujadAs (2020), los procesos de suburbanización y, por tanto, las periferias metropolitanas son atractivas para buena parte de la población, debido al boom inmobiliario que padecen las ciudades centrales, ante los fenómenos de 
creciente turistificación, financiarización y de incremento del precio de los arrendamientos urbanos. La elitización de las capitales y sus centros es una dinámica creciente en las principales ciudades europeas, tal y como también se constata en Madrid (TAMMARU \& al., 2018) y Barcelona (LóPEZ-GAY, 2018). Ambas ciudades presencian un proceso de fragmentación de los barrios populares que contrasta con el aumento en extensión, agrupación y homogeneidad de las zonas más elitizadas de clase alta (Rubiales, 2020). Como señala Moskowitz (2017), la gentrificación puede ser considerada como una manifestación de lógicas del capital, aunque la percibamos como un gran número de iniciativas individuales de gentries que compran o alquilan vivienda.

Así la población con estudios universitarios tiende a igualarse y a concentrarse en las capitales metropolitanas haciendo más diferentes los barrios de estas grandes ciudades del resto del territorio metropolitano. También destaca la pérdida de importancia relativa de clases populares (nacionales y extranjeras) en zonas muy concretas del centro: en Tetuán y Centro, en el caso de Madrid; así como en los barrios de Gòtic, Sant Pere, Santa Caterina i la Ribera y Glòries, en el caso de Barcelona. Rubiales (2020) etiqueta el proceso como una polarización desigual: por un lado, zonas de clase alta que se expanden, se agrupan y se reconcentran más, y, por otro, zonas populares que también se expanden y se concentran, pero de forma más fragmentada. Sea por desplazamiento o transformación de la estructura o, más probablemente, por una combinación de estos dos procesos, el proceso de elitización y gentrificación de ambas capitales resulta evidente, así como la extensión en ellas de la población (nacional o extranjera) con estudios universitarios. Esta progresiva elitización de los centros tiene una fuerte capacidad de visibilidad colectiva. Los datos así lo demuestran. La tasa de titulados superiores pasa del $13,7 \%$ (en 2001) al $23,7 \%$ (en 2011) y al $32,3 \%$ (en 2019) para el caso de Ciutat Vella en Barcelona, incrementándose en 18 puntos; mientras que, en Madrid, parte del $20,3 \%$ en 2001 y pasa al $31,9 \%$ en 2011 y más recientemente, al 44\% cuando la media en Madrid es del $37 \%$ (Padrón 2020). Esto es, un incremento de 24 puntos según datos del Censo de Población y Vivienda y datos del Padrón de 2020.

Según LEES (2003), la gentrificación, que se ve reforzada por el fenómeno de turistificación, da lugar a CENTROS con una vasta presencia de turistas y población flotante, reduciendo la población de clase baja e inmigrantes más vulnerables, así como contribuyendo a la desaparición del comercio tradicional. Esta capacidad de atraer a población altamente cualificada y con altas rentas en posteriores oleadas (lo que LEES (2003) denomina "supergentrificación"), apunta a pensar que en determinados sectores de la ciudad la vivienda se ha convertido en un bien exclusivo (y excluyente) y que ese área de exclusividad se ha expandido desde los barios centrales, provocando una progresiva suburbanización de la pobreza (HOCHSTENBACH \& MUSTERD, 2016). Los cambios en el sistema de tenencia, con la aparición y la consolidación del alquiler como una alternativa a la propiedad (MóDENES \& LóPEZ-CoLÁs, 2014), el encarecimiento del precio de las viviendas, tanto de alquiler como de compra y el endurecimiento de las condiciones para conseguir un crédito hipotecario, tienen también incidencia sobre el comportamiento de la movilidad residencial (LóPEZ-GAY, 2017). Los vecinos ponen de manifiesto la inevitabilidad del proceso de cambio y de expulsión de la población:

\footnotetext{
"La gentrificación es un monstruo que se va... empezaron con lo de los... con lo de quitar los alquileres de bajo coste, de renta antigua, vamos, empezó por ahí... y a pasos agigantados está comiendo el barrio, por muchas asambleas de barrio que haya, por muchos intentos de parar los desahucios, por mucho que exista stop desahucios, por mucho que exista toda la... la menos presente la Fiambrera obrera, por mucho que exista Lavapiés dónde va, que es la plataforma de gestión y de denuncias de procesos gentrificados del barrio... por más que se haga, y por más que se haga pues... la cosa va para donde va..." (ENTREVISTA M2).

"Desde que llegué al barrio en enero de 2016 a día de hoy, la suciedad se ha incrementado. A pesar que los Servicios Municipales pasan dos veces al día, sigue sucio. El tema de los narcopisos se ha paralizado, por suerte, aunque cerca de casa había tres que supiéramos, ahora están parece cerrados...y claro, esta gente te incomoda, gente entrando y saliendo, pinchándose en la calle, al lado de las basuras...en la calle, jugaban niños...pero a partir de determinado momento ya no había niños jugando a la calle...pero con la droga las madres encerraran los niños en casa... también la remodelación de la plaza de Folch y Torres...ha hecho que los niños jueguen allá... (ENTREVISTA B4).
}

Paralelamente o en algunos casos, previo a la turistificación, se evidencia un proceso de trendificación o sustitución del comercio tradicional por comercio más moderno y destinado a los gentries, turistas, visitantes, etc., incentivando el desplazamiento de grupos de población y de comerciantes localizados en áreas centrales o valorizadas (CORDERO \& SALINAS, 2017; GonZÁLEZ \& WALEY, 2013; HERNÁNDEZ 
\& ANDREEVA, 2016; SALINAS, 2015). Esto es, que los comercios tradicionales que abastecían a la población residente tradicional se transforman para satisfacer la demanda de sectores de población identificados con nuevas pautas de consumo como son los turistas, gentries y estudiantes. De igual modo, los propietarios de estos negocios cambian desde el pequeño comerciante individual a los grupos colectivos o grandes cadenas. En paralelo, la mayoría de las tiendas cambian de tradición y así se revaloriza el consumo de los productos frescos y de proximidad en tiendas cool y espacios vintage. Tal fenómeno se conoce como trendification o aburguesamiento por el comercio. Algunas tiendas se han especializado en productos para familias jóvenes y productos ecológicos y de proximidad: queserías, vinos, productos orgánicos y delicatessen, de payés. Un público con más poder adquisitivo y con gustos etiquetados como de alimentación saludable. De este modo, el comercio tradicional ha ido cerrando, pero no solamente en el centro urbano, sino también en las periferias y áreas circundantes de las áreas de influencia turística. Nuevamente, se evidencia la inevitabilidad del proceso:

"Habitualmente los comercios no siguen más de dos generaciones. Esta, en muchos de los establecimientos es la última, los hijos no quieren puestos de trabajo o negocios tan esclavos en horarios (de 9 a 9 ) e inclusive en fines de semana. Solo sobrevive el comercio tradicional que ha hecho un cambio tecnológico digital (que también ofrece venta on-line), o tiene una clientela muy fija porque se ha especializado enormemente". (ENTREVISTA B1).

HYDE (2014) analiza estos procesos de gentrificación comercial en las ciudades. Procesos impulsados por los gustos diversificados de las clases más altas con necesidades de experiencias urbanas y turísticas auténticas (DWYER, \& al., 2009) especialmente de índole cultural (JOHNSTON \& BAUMANN, 2007), gastronómica (MARTIN, 2014) o ambas, siendo los mercados de abastos transformados en mercados gourmets uno de los iconos más representativos como reclamos de espacios tradicionales y/o simbólicos (CRESPI-VALLBONA \& DOMíngUEZPÉReZ, 2016; Medina \& Álvarez, 2009; Coles, 2014). Los cambios comerciales indican también hasta qué punto la ciudad se turistifica así como gentrifica (BRIDGE \& DoWLING, 2001). Las zonas comerciales y los negocios dejan de orientarse a los clientes locales, para focalizarse en los temporales visitantes que aportan copiosos beneficios (Hernández PeZZI, 2018) o los nuevos residentes de nivel socioeconómico más elevado. El patrón estético historicista (retro o vintage) y nostálgico invade los bares, las tiendas, las salas de espera, los negocios. La estética de lo bello, antiguo, auténtico, con una mirada romántica (URRY \& LARSEN, 2011):

"Fíjate, ¿conoces el barrio? Allí, allí acaban de cerrar la droguería, y la tienda de quesos y pasta fresca que tan bien nos iba... pues claro, también ha cerrado, ¿para qué? para claro, abrir un bareto, con su terraza... lo de siempre..." (ENTREVISTA B4).

"El barrio me gusta, es céntrico, hay una oferta cultural increíble, porque están tres salas de teatro cerca de casa, con bares y restaurantes a pesar de la droga... pero claro no conozco a la gente del barrio, no hago cosas con ellos... pero me ofrece oferta comercial mixta, comercios indios, marroquíes, pakistaníes, de otras culturas y zonas y yo lo valoro mucho..." (ENTREVISTA B3).

"antes eran familias que vivían allí, tenemos que empezar a pensar que eran familias que hacían barrio, que bajaban a la panadería, que bajaban a la lechería, iban a los mercados; ahora ya no, eso ya ha cambiado sino que ahora es un turismo que viene, que se va a estas grandes superficies a cualquier hora del día, porque la gente cuando está de vacaciones está de fiesta más o menos, y luego no es gente que dé calidad al barrio, porque es gente que viene aquí a visitar museos a visitar campos... los Real Madrid, pero aquí a los bares pues a lo mejor vienen a desayunar o van a estas grandes superficies compran para desayunar en su casa, es decir, que en todo este tiempo ha evolucionado mucho..." (ENTREVISTA M4).

Desde el punto de vista social, el comercio proporciona dinamización en el territorio y el barrio, así como interacción social y cohesión entre los vecinos de la comunidad. Así, lo que más valoran los residentes es la especialización de las tiendas del barrio, la cotidianeidad, las redes tejidas, el encuentro, los servicios, etc. tanto en Barcelona como en Madrid. Sin embargo, evidencian que todo ello se va perdiendo:

"Pues claro, si vivo aquí y me tengo que ir hasta San Carlos, seguro que en el camino me encuentro a una o dos personas... y hablas, y tienes... entonces eso es lo que me gusta. (...) Si, porque es que así te enteras de que... de muchas cosas... fijate que han cerrado este sitio... pues una perfumería que llevaba toda la vida en la calle Mesón de Paredes, la han cerrado (...) Si, si no pasas no te enteras... entonces te enteras "ay, joder pues han cerrado otro sitio" ... no es yo fuera... pero que la había... han cerrado esto, y que pena, que pena porque es un comercio tradicional que ha desaparecido y sobre todo va a ver de qué hablar..." (ENTREVISTA M3).

La ausencia de comercio, la desertización de los locales comerciales, la falta de atractivo de estos o una orientación que no responda a los 
intereses del vecindario, generan disfunciones y degradación del espacio público. Por ello, se considera el comercio como uno de los pilares de la sostenibilidad de los barrios, la mejora del espacio público, la potenciación de un espacio de encuentro entre la población permanente, la temporal y la visitante. $Y$ es que, como señala JACOBS (2011), el comercio construye ciudad. También entre los propios comerciantes. Habitualmente existe entre ellos una red, pero actualmente la rotación comercial es alta, se registra un goteo de salidas, se evidencia más individualismo y desmovilización y así van dejando de ser un colectivo organizado y reivindicativo. No obstante, en algunos casos, emerge la formación de una conciencia común y resistencia que se articula en movimiento social:

"Cuando el mercado nos vayamos todos los que somos autoempleo, diremos, "joder ¿qué paso? ¿por qué paso esto?" bueno, te voy a explicar, te voy a explicar por qué ha pasado esto: porque este no vendía, porque el otro no abría, porque el otro abría pero no tenía que vender; entonces claro, dices "joder", es un poco grado de implicación en las cosas, es un poco grado de implicación y decir "¿hasta dónde estamos dispuestos a llegar?", ¿hasta dónde estamos dispuestos a llegar? porque yo hay días que levanto la persiana y la bajo y digo "joder, mejor en mi casa que por lo menos estoy tumbado o leo o hago otras cosas", pero es una cuestión también de decir "no" esto es una carrera de fondo, aquí hay que seguir, hay que aguantar, hay que aguantar y además decir "es que no me tiene por qué echar esta persona, no me tiene por qué echar porque esto es mío" es mío y no... y es un espacio público, y es algo por lo que hemos luchado y por lo que hay que seguir luchando, hay que seguir para conseguirlo porque además, seguro que lo conseguimos, pero claro, seguro que lo conseguimos si hay compromiso, si hay compromiso por parte de todos y un compromiso con cierta constancia... mantenido. Mantenido que es... que luego cuando cierro tengo que ir a protestar, pues voy a protestar o que cojo y digo... "ah, que hay una huelga feminista" "y esto ¿cómo se puede apoyar?”, de esta manera, pues voy a apoyarlo. ¿Por qué? Porque... oye, pero ese día no vas ingresar, pero bueno, ya, pero es que es un objetivo superior, es una cosa, es un bien común; es un bien común" (ENTREVISTA M3).

Por otro lado, junto a gentries y turistas, la estudentificación también acompaña estos procesos de transformación urbana y también contribuye a generar nuevas modas y comportamientos (SMITH, 2005). Se trata de una población móvil también, que revitaliza el espacio público y lúdico y que se ha visto revalorizada en distintas ciudades europeas. En los centros urbanos aparecen residencias y viviendas o edificios para estudiantes de la mano de grandes grupos inversores que ven en este sector una nueva fuente para explotar ciudades (EL PAís, 2019; El CONFIDENCIAL, 2019; EXPANSIÓN, 2020). Se trata de un nuevo nicho de inversión lucrativa, sobre todo como pisos y residencias de estudiantes internacionales con más poder adquisitivo. Esto es, que puede ser considerado como una tendencia y un punto de interés para las Socimis y el capital extranjero en general. Concretamente y durante los últimos años, se ha constituido en uno de los sectores de interesante inversión para el capital; sobre todo, en Madrid y principalmente Barcelona. La población de los barrios así lo pone de manifiesto:

\footnotetext{
“... lo que nos suena más o lo que conocíamos más eran los pisos de estudiantes que eran piojeras, que eran... entraban y salían y tal, pero era una cosa divertida, lúdica," (ENTREVISTA M1).
}

\begin{abstract}
"Ahora, Lavapiés tiene una población alta de estudiantes. Estudiantes en su gran mayoría europeos... entonces gente que viene de Erasmus, se radica en el barrio un año, y luego se pira... y eso también ha ayudado a que los pisos se encarezcan, ¿por qué? Porque bueno, la economía que tiene una persona que viene esponsorizado por sus padres, aparte de eso la universidad le ha dado una beca, viene de Holanda, de Alemania, que una beca en Holanda no es lo mismo que una beca aquí en España, que aquí para obtener una beca, que sea relativamente, que cumpla unas funciones mínimas, es complicadísimo... mientras que esta gente viene y se puede acomodar tranquilamente pagando 450 o 500 euros por una habitación..." (ENTREVISTA M2).
\end{abstract}

Financiarización. Por último, mientras que en algunos casos el motor de la reestructuración urbana y la gentrificación es la trendificación, que atrae a su vez a las clases medias y mediasaltas; en otras ciudades, son las corporaciones, principalmente financieras e inmobiliarias, las que protagonizan el proceso (MÉNDEZ, 2018, 2019). Estas últimas son las que intervienen en el incremento del valor y del precio de la propiedad y alquiler de las viviendas. La gentrificación de estos barrios se acompaña de una homogeneización social y cultural, y de una privatización del espacio público. La carrera competitiva de las ciudades para atraer turismo intensifica la función de la ciudad como un producto de mercado. Los grupos inversores compran edificios residenciales enteros para convertirlos en alojamiento turístico (GURRAN \& PHIBBS 2017; SASSEN 2015; SASSEN \& DíAZ, 2018). Es llamativo que alrededor de la mitad de las ofertas de Airbnb en 2017 en Madrid pertenece a propietarios que tienen más de una oferta, esto es, a grupos inversores o a inversores individuales (AYUNTAMIENTO DE MADRID, 2016). Esto 
significa que no se trata de economía colaborativa, sino de verdaderas inversiones masivas en vivienda para su rentabilización.

Como se ve en el caso español, 2013 fue el punto de inflexión en las tendencias descritas por los distintos procesos aquí señalados y coincide también con la irrupción de las Socimis en el panorama español y sus crecientes inversiones en inmobiliario y en el sector del alquiler (vivienda, sobre todo, y locales, oficinas, tiendas comerciales). Las Socimis se crean en plena crisis (2009) pero se desarrollan sobre todo a partir de 2013. Muchas de ellas cuentan con amplia participación internacional. Sus áreas de interés son también las residencias universitarias, los coliving, etc. y cuentan con amplios beneficios fiscales y han popularizado la inversión inmobiliaria en España. Los grandes grupos se lucran con el negocio de la vivienda en múltiples variedades.

\section{Conclusiones}

En la actualidad, las ciudades, y sobre todo algunas más que otras, se ven afectadas por el turismo y su atractivo para las mismas y paralelamente por otros procesos que lo acompañan (gentrificación, trendificación, estudentificación, etc). La industria del turismo se revela como una fuente de desarrollo local para estas y es así de gran interés. En su interior, los centros urbanos, como espacios donde se concentra el patrimonio e historia de las ciudades y que cuentan con ventajas de posicionamiento urbano para muchos sectores, son los espacios más afectados por ello.

Entre los diversos impactos sobre el centro, uno de los más destacados es el desplazamiento, físico y simbólico, de los sectores más vulnerables, en favor de los más acomodados, erosionando su derecho a la ciudad.

Pero, sin embargo, como se ha reseñado, no solamente los centros urbanos se ven afectados por el turismo, sino que son varias las tendencias que presionan sobre los mismos provocando efectos diferenciados. De fondo, subyace la lógica del neoliberalismo que a través de distintos formatos impacta sobre la ciudad y sus centros. Así, la trendificación, estudentificación, financiarización, etc, además de la turistificación, impactan sobre estos espacios mediante dinámicas correlativas que condicionan las actitudes y percepciones de la población residente, al tiempo que mediante mecanismos urbanísticos (alza de precios, desahucios, ejecuciones, declive del comercio de proximidad, etc.) y culturales así como simbólicos (cambio en el estilo de vida del centro y atmósfera), se presiona al desplazamiento de la población residente. Consiguientemente la población del centro, convive con nuevos sectores que van incorporándose pero que poco a poco van desplazándolos a través de distintos mecanismos.

Así después de este análisis de las dinámicas que afectan a los centros urbanos, primeramente, a través de los datos cuantitativos, pero también del discurso de los residentes, se evidencia que la población del centro continúa cambiando. No solo a través de la turistificación sino de otros procesos, el centro urbano va convirtiéndose en un espacio turistificado, elitizado, ludificado y gentrificado. Esto es, un espacio del que se apropian los visitantes, los residentes de poder adquisitivo medio y alto, los inmigrantes internos procedentes sobre todo de la Unión Europea, los estudiantes de elevado nivel adquisitivo, los amantes de una oferta cultural amplia y variada, con diversidad de opciones comerciales, gastronómicas y de consumo lúdico. Todos ellos llegan a unos barrios, en general de menor nivel socioeconómico, y comienzan a coexistir, que no convivir, junto a los residentes tradicionales; mientras la maquinaria se ha puesto en funcionamiento para ir expulsándolos mediante el alza de precios de los alquileres y la escasez, así como por el cambio de estilo de vida del barrio hacia un modelo que potencia la movilidad y no el arraigo. Poco a poco, los antiguos pobladores, las clases populares, los inmigrantes, los mayores, comerciantes tradicionales, etc. se fragmentan y van desapareciendo. Estos sectores tradicionales, más vulnerables, se ven impelidos y presionados por diversas dinámicas hacia el desplazamiento. En el lado contrario, los nuevos pobladores, pertenecientes a sectores más acomodados, que sintonizan entre sí en torno a intereses y estilos de vida compartidos, sintiéndose pertenecientes a un espacio urbano central que sienten suyo, comienzan a articular redes y discursos cohesionadores. De este modo, el centro va fragmentando unos estilos de vida al tiempo que tejiendo otros entre los que comparten un estilo de vida, unos gustos, unos intereses, un consumo cultural y lúdico, entre los que tienen un poder de renta medio y medio alto.

Estos dos mundos coexisten en los centros urbanos estableciéndose tensiones entre ellos. Se trata de una dinámica propia de los procesos urbanos que comparten las ciudades contemporáneas europeas de hoy. Así cuando estos grupos de población (turistas, estudiantes internacionales, inmigrantes universitarios de la UE, 
clases medias y medias altas, etc.) alcanzan cierta masa crítica, son capaces de "hacer barrio" dejando sentir en él su impronta, visibilizándose e inclinando la balanza en pos de sus intereses. Estos elementos de identidad, inclusión y bienestar son la base de la transformación global de la vida comunitaria en una ciudad de corte neoliberal donde imperan los intereses de las clases altas y el capital. Poco a poco estos centros urbanos pasan de ser espacios de diversidad y encuentro a ser nuevos espacios homogeneizados y de nivel socioeconómico más elevado, como el resto del centro. La actual pandemia de la Covid19 es de esperar que intensifique estos procesos una vez se vaya recuperando la economía mediante la sustitución definitiva de las clases más vulnerables y afectadas por la crisis, con la entrada de las nuevas clases emergentes y la turistificación, cuando ello sea posible, a no ser que las tendencias sean revertidas. El efecto inmediato de la pandemia ha supuesto un freno al turismo, provocando la migración de la vivienda turística al mercado residencial; sin embargo, los elevados precios del centro en un marco de crisis generalizada y sobre todo para ciertos colectivos, potenciará y consolidará presumiblemente el cambio urbano apuntado desde hace décadas, esperando tiempos mejores para el turismo.

\section{Bibliografía}

AYUNTAMIENTO DE MADRID (2016): Análisis del impacto de las VUT en el distrito centro de Madrid, Madrid.

BayonA-I-CARRASCo, J. \& PuJAdAS I. (2020): Las grandes áreas metropolitanas en España: del crecimiento y la expansión residencial al estancamiento poblacional. Documents d'Anàlisi Geogràfica, 66 (1), 27-55.

BAPTISTA, L. (2005): Territórios lúdicos (e o que torna lúdico um território): Ensaiando um ponto de partida, Fórum Sociológico, 13/14,47-58.

BBVA, (2020) Urban Discovery.

https://www.bbvadata.com/urban-discovery-a-vision-to-rethink-cities/ (consultado 16 de febrero 2021).

BENACH, N. (2016): ¿Ciudades en el mapa o en la guía turística? Venta de la ciudad y sentido del lugar. Revista Cidob d'afers internacionals, 113, 89-105.

BRIDGE, G., \& DowLING, R. (2001): Microgeographies of retailing and gentrification. Australian Geographer, 32(1), 93-107.

CAZES, G. (1998): "La renovación del turismo urbano. Problemática de investigación", 81-87. En Manuel Marchena (ed.): Turismo urbano y patrimonio cultural. Una perspectiva europea. Sevilla: Diputación Provincial.

CócolA, A. (2016): Holiday rentals: The new gentrification battlefront. Sociological Research Online, 21(3), 1-9.
Coles, B.F. (2014): Making the Marketplace: a topography of Borough Market, London. Cultural Geographies. 21(3), 515-523.

COLOMB, C. (2007): Unpacking new labour's "Urban Renaissance" agenda: Towards a socially sustainable reurbanization of British cities? Planning, practice \& research, 22 (1), 1-24.

CORDERO, L. \& SALINAS, L. (2017): Gentrificación comercial. El modelo de los mercados gourmet. Revista de Urbanismo, 37, 1-12.

CRespi-VallbonA, M. \& Domínguez-PÉReZ, M. (2016): Los mercados de abastos y las ciudades turísticas. Pasos. Revista de Turismo y Patrimonio Cultural, 14 (2), 401-416.

Cucó, J. (ed.) (2013): Metamorfosis urbanas. Ciudades españolas en la dinámica global. Barcelona: Icaria.

DELGADO, M. (2003): "Los efectos sociales y culturales del turismo en las ciudades históricas", 355-375. En VV.AA. Desarrollo turístico integral de ciudades monumentales. Granada: Patronato de Turismo.

DWYER, L. \& al., (2009): Destination and enterprise management for a tourism future. Tourism management, 30(1), 63-74.

El Confidencial (2019): 28 de junio de 2019: https://www.elconfidencial.com/empresas/2019-0628/inversion-residencias-de-estudiantes-habitaciones 2083207/ (consultado el 8 de marzo de 2020).

EL PAís (2019): 14 diciembre 2019: https://elpais.com/economia/2019/12/12/actualidad/ 1576160624 084182.html (consultado el 8 de marzo de 2020).

EuRopean CitIEs MARKeting (2018): European Cities Marketing Benchmarking Report. Dijon: ECM.

EXPANSIÓN (2020): 4 de febrero de 2020: https://www.expansion.com/empresas/inmobiliario |2020/02/04/5e39146ae5fdeafb468b4639.html (consultado el 8 de marzo de 2020).

FOESSA (2019): VIII Informe sobre exclusión y desarrollo social en España, https://www.foessa. es/viii-informe/ (consultado 19 de octubre de 2020).

FüLLER, H., \& MICHEL, B. (2014): "Stop Being a Tourist!" New Dynamics of Urban Tourism in BerlinKreuzberg. International Journal of Urban and Regional Research, 38(4), 1304-1318.

Gallagher, L. (2017): The Airbnb story: How three ordinary guys disrupted an industry, made billions ... and created plenty of controversy. Houghton Mifflin Harcourt: Boston, U.S.A.

GoNZÁLEZ, S. \& WALEY, P. (2013): Traditional Retail Markets: The New Gentrification Frontier. Antipode: a radical journal of geography. 45, 965-983.

GuRRAN, N. \& PhiBBS, P. (2017): When tourists move in: How should urban planners respond to Airbnb? Journal of the American Planning Association, 83(1), 80-92.

HARVEY, D. (2004): El "nuevo" imperialismo. Acumulación por desposesión. Socialist Register 40, 63-87.

Hernández, A. \& ANDReeva, S. (2016): ¿Mercados, museos o malls? La gentrificación de los mercados municipales en Barcelona y Madrid. EntreDiversidades, Revista de Ciencias Sociales y Humanidades. 6, 143- 173.

HeRnÁndez Pezzl, C. (2018): Turismo: truco o trato. Políticas públicas urbanas para el turismo de masas. Madrid: Catarata. 
Hochstenbach, C. \& Musterd, S. (2018): Gentrification and the suburbanization of poverty: Changing urban geographies through boom and bust periods. Urban Geography, 39(1), 26-53.

HYDE, Z. (2014): Omnivorous Gentrification: Restaurant Reviews and Neighborhood Change in Downtown Eastside of Vancouver. City \& Community. 13(4), 341-359.

IDEALISTA (2020): Evolución de los precios de la vivienda en alquiler y compra.

(https://www.idealista.com/sala-de-prensa/informes-precio-vivienda/ consultado 19 de octubre de 2020).

INFORME AXESOR (2019): Una comparación odiosa Madrid versus Barcelona. https://trizelegal.es/ una-comparacion-odiosa-madrid-vs-barcelonal (consultado 19 de octubre de 2020).

INSIDE AIRBNB (2016): Analysis of "Entire homes/ apartments" and "private rooms" in Barcelona http:// insideairbnb.com/barcelona/\# (consultado $19 \mathrm{de}$ octubre de 2020).

- (2020): Portal estadístico de datos de ciudades del mundo. http://insideairbnb.com/get-the-data.html (consultado 19 de octubre de 2020).

INE (2016): Instituto Nacional de Estadística. Nuevos datos de renta por secciones censales. Renta 2016. https://elpais.com/economia/2019/09/11/ actualidad/1568217626 928704.html (consultado 16 de febrero 2021).

- (2020): Instituto Nacional de Estadística. Mercado laboral. www.ine.es (consultado 19 de octubre de 2020).

JACOBS, J. (2011): [1961] Muerte y vida de las grandes ciudades, Madrid: Capitán Swing.

Johnston, J. \& BAUMANN, S. (2007): Democracy versus Distinction: a Study of Omnivorousness in Gourmet Food Writing. American Journal of Sociology. 113(1), 165204.

LANFANT, M. (1994): Identité, mémoire et la touristification de nos sociétés. Sociétés. Revue des Sciences Humaines et Sociales, 46, 433-439.

LEES L. (2003): Super-Gentrification: The Case of Brooklyn Heights, New York City, Urban Studies, 40 (12), 2487-2509.

- (2016): Gentrification, race, and ethnicity: towards a global research agenda? City \& community, 15(3), 208-214.

LeZAMA, J. L. (2014): Teoría social, espacio y ciudad. El Colegio de Mexico AC.

LóPEZ-GAY, A. (2017): Hacia un patrón territorial complejo de la movilidad residencial. Papers, 102(4), 793-823.

- (2018): Cambio en la composición social y gentrificación en Barcelona: Una mirada a través de los flujos migratorios y residenciales. Papers: Regió Metropolitana de Barcelona: Territori, estratègies, planejament, 60, 80-93.

- \& Cocola GANT, A. (2016): “Cambios demográficos en entornos urbanos bajo presión turística: el caso del barri Gòtic de Barcelona", in Domínguez-Mújica, J. and Díaz-Hernández, R. (ed.), XV Congreso Nacional de la Población Española, Fuerteventura: Asociación de Geógrafos Españoles, pp. 399-413.

MAITLAND, R. (2010): Everyday life as a creative experience in cities. International Journal of Culture, Tourism and Hospitality Research, 4(3), 176-185.
MARTIN, N. (2014): Food Fight! Immigrant Street Vendors, Gourmet Food Trucks and the Differential Valuation of Creative Producers in Chicago. International Journal of Urban and Regional Research, 38 (5), 1867-83.

Martín, J. M. \& GuaitA, J. M. \& Salinas, J. A. (2018a): An Analysis of the Factors behind the Citizen's Attitude of Rejection towards Tourism in a Context of Overtourism and Economic Dependence on This Activity. Sustainability, 10(8), 2851-2863.

MedinA, X. \& Álvarez, M. (2009): El lugar por donde pasa la vida... Los mercados y las demandas urbanas contemporáneas: Barcelona y Buenos Aires. Estudios del hombre, 24, 183-201.

MÉNDEZ, R. (2018): La telaraña financiera: Una geografía de la financiarización y su crisis. RIL Editores.

- (2019): Ciudades en venta. Estrategias financieras y nuevo ciclo inmobiliario en España. Universidad de Valencia.

MódENES, J. A. (2019): L'insostenible augment de la inseguretat residencial a Espanya. Perspectives Demogràfiques, 13.

— \& LóPEZ-ColÁs, J. (2014): Cambio demográfico reciente y vivienda en España: ¿Hacia un nuevo sistema residencial? REIS: Revista Española de Investigaciones Sociológicas [en línea], 148, 103-33.

Moskowitz, P. E. (2017): How to kill a city: Gentrification, inequality, and the fight for the neighborhood. Bold Type Books.

Novy, J. (2017): "The Selling (Out) of Berlin and the De- and Re-politicization of Urban Tourism in Europe's "Capital of Cool»", in Colomb, C. and Novy J., Protest and Resistance in the Tourist City, London: Routledge.

PLANOS DE MADRID (2020): Guía Comercial de Madrid Empresas y Servicios.

(https://www.planosdemadrid.es/en-el-plano-demadrid/hoteles-en-el-mapa.html consultado $19 \mathrm{de}$ octubre de 2020).

PORCEL LóPEZ, S. \& al., (2018): La suburbanització de la pobresa com a efecte metropolità de la gentrificació: el cas de Barcelona. Papers: Regió Metropolitana de Barcelona: Territori, estratègies, planejament, (60), 0094-113.

PROVIVIENDA (2018) Cuando la casa nos enferma. Informe:

https://www.provivienda.org/informe-cuando-lacasa-nos-enferma-la-vivienda-como-cuestion-desalud-publica/ consultado 16 de febrero 2021.

PROYECTO VUPACI (2015-18): Vulnerabilidad, participación y ciudadanía. Claves para un desarrollo urbano sostenible (Referencia: S2015/HUM-3413VUPACICM). IP: Marta Domínguez Pérez. Financiado por Comunidad de Madrid y Unión Europea.

Quaglieri Domínguez, A. \& Scarnato, A. (2017): "The Barrio Chino as last frontier: the penetration of everyday tourism in the dodgy heart of the Raval", 107-133 in Gravari-Barbas, M. and Guinand, S.: Tourism and Gentrification in Contemporay Metropolises. Routledge: New York.

RICHARDS, G. (2016): El turismo y la ciudad ¿Hacia nuevos modelos? Revista Cidob d'afers internacionals, 113, 71-87. 
Rubiales, M. (2020): Segregación en las metrópolis españolas 2001-2011: un análisis con detalle territorial. Documents d'Anàlisi Geogràfica, 66 (1), 83-105.

Russo, A. P. (2015): "La explosión del turismo colaborativo y los retos para el modelo turístico español", 113-134. En Aguiló Pérez, E. y Antón Clavé, S., 20 retos para el turismo en España. Madrid: Pirámide.

— \& ARIAS-SANS, A. (2017): "The Right to Gaudí. What Can We Learn from the Commoning of Park Güell, Barcelona?", in Colomb, C. and Novy, J. (ed.), Protest and Resistance in the Tourist City, London: Routledge.

SALINAS, L. (2015): Transformación de mercados municipales de Madrid. De espacio de consumo a espacio de esparcimiento. Revista INVI, 85, (31), 179-201.

Salvi Del Pero, A., \& al. (2016): "Policies to promote access to good-quality affordable housing in OECD countries", OECD Social, Employment and Migration Working Papers, No. 176, OECD Publishing, Paris, https://doi.org/10.1787/5jm3p5gl4djd-en. (Consultado 19 de octubre de 2020).

SASSEN, S. (2015): Expulsiones: brutalidad y complejidad en la economía global. Buenos Aires, Katz editores.

— \& DíAz, F. (2018): Sobre expulsiones. ARQ (Santiago), (98), 14-25.

SMITH, D.P. (2005): "Studentification: the gentrification factory", 72-89. In Atkinson, R. and Bridge, G. (Eds): Gentrification in a Global Context. London: Routledge.

SMITH, N. (2002): New globalism, new urbanism: gentrification as global urban strategy. Antipode 34, 427-450.

TAMMARU, T.; \& al., (2018): Relationship between income inequality and residential segregation of socioeconomic groups. Regional Studies, 1-12.

URRY, J. \& LARSEN, J. (2011): The tourist gaze 3.0. Sage.

URZÚA BASTIDA, V. (2012): El espacio público y el derecho a excluir. Athenea Digital, 12 (1), 159-168. 